\title{
A Review on Graphene-Based Gas/Vapor Sensors with Unique Properties and Potential Applications
}

\author{
Tao Wang ${ }^{1}$ Da Huang ${ }^{1}$ Zhi Yang ${ }^{1,2} \cdot$ Shusheng $\mathrm{Xu}^{1} \cdot$ Guili He $^{1}$ • \\ Xiaolin $\mathrm{Li}^{1} \cdot$ Nantao $\mathrm{Hu}^{1} \cdot$ Guilin $\mathrm{Yin}^{2} \cdot$ Dannong $\mathrm{He}^{2} \cdot$ Liying Zhang ${ }^{1}$
}

Received: 17 July 2015/Accepted: 31 August 2015/Published online: 26 November 2015

(C) The Author(s) 2015. This article is published with open access at Springerlink.com

\begin{abstract}
Graphene-based gas/vapor sensors have attracted much attention in recent years due to their variety of structures, unique sensing performances, room-temperature working conditions, and tremendous application prospects, etc. Herein, we summarize recent advantages in graphene preparation, sensor construction, and sensing properties of various graphene-based gas/vapor sensors, such as $\mathrm{NH}_{3}, \mathrm{NO}_{2}, \mathrm{H}_{2}, \mathrm{CO}, \mathrm{SO}_{2}, \mathrm{H}_{2} \mathrm{~S}$, as well as vapor of volatile organic compounds. The detection mechanisms pertaining to various gases are also discussed. In conclusion part, some existing problems which may hinder the sensor applications are presented. Several possible methods to solve these problems are proposed, for example, conceived solutions, hybrid nanostructures, multiple sensor arrays, and new recognition algorithm.
\end{abstract}

Keywords Graphene - Gas/Vapor sensor · Chemiresistor - Detection mechanism

\section{Introduction}

The past several decades have witnessed a tremendous development of chemical sensors in many fields [1-4]. Gases detecting and harmful vapors with early warning feature are playing increasingly important roles in many fields, including environmental protection, industrial manufacture, medical diagnosis, and national defense. Meanwhile, sensing materials are of intense significance in promoting the combination properties of gas/vapor sensors, such as sensitivity, selectivity, and stability. Thus, various materials [5-13], covering from inorganic semiconductors,

\footnotetext{
Zhi Yang

zhiyang@sjtu.edu.cn

Liying Zhang

liyingzhang@sjtu.edu.cn

1 Key Laboratory for Thin Film and Microfabrication of Ministry of Education, Department of Micro/Nano

Electronics, School of Electronic Information and Electrical Engineering, Shanghai Jiao Tong University, Shanghai 200240, People's Republic of China

2 National Engineering Research Center for Nanotechnology, Shanghai 200241, People's Republic of China
}

metal oxides, and solid electrolytes, to conducting polymers, have been exploited to assemble sensing devices with small sizes, low power consumption, high sensitivity, and long reliability. Among them, nanomaterials, such as carbon nanotubes (CNTs), metal-oxide nanoparticles, and graphenes, are widely used in gas sensing for their excellent responsive characteristics, mature preparation technology, and low cost of mass production, since the traditional silicon-based semiconducting metal-oxide technologies will have reached their limits [14]. Figure 1 shows a module of MQ-9, a $\mathrm{SnO}_{2}$-based gas sensor for $\mathrm{CO}$ detection, which can be easily obtained in the market.

As one of the most fascinating materials, graphene has aroused scientists' great enthusiasms in its synthesis, modification, and applications in many fields since 2004 [15], due to its remarkable overall properties, for instance, single-atom-thick two-dimensional conjugated structures, room-temperature stability, ballistic transport, and large available specific surface areas [16-39]. Graphene can be served as an ideal platform to carry other components for specific roles, because of its special structure. High conductivity and ballistic transport ensure that graphene exhibits very little signal disturbance when it works as a chemical sensor [40], which do not require auxiliary 


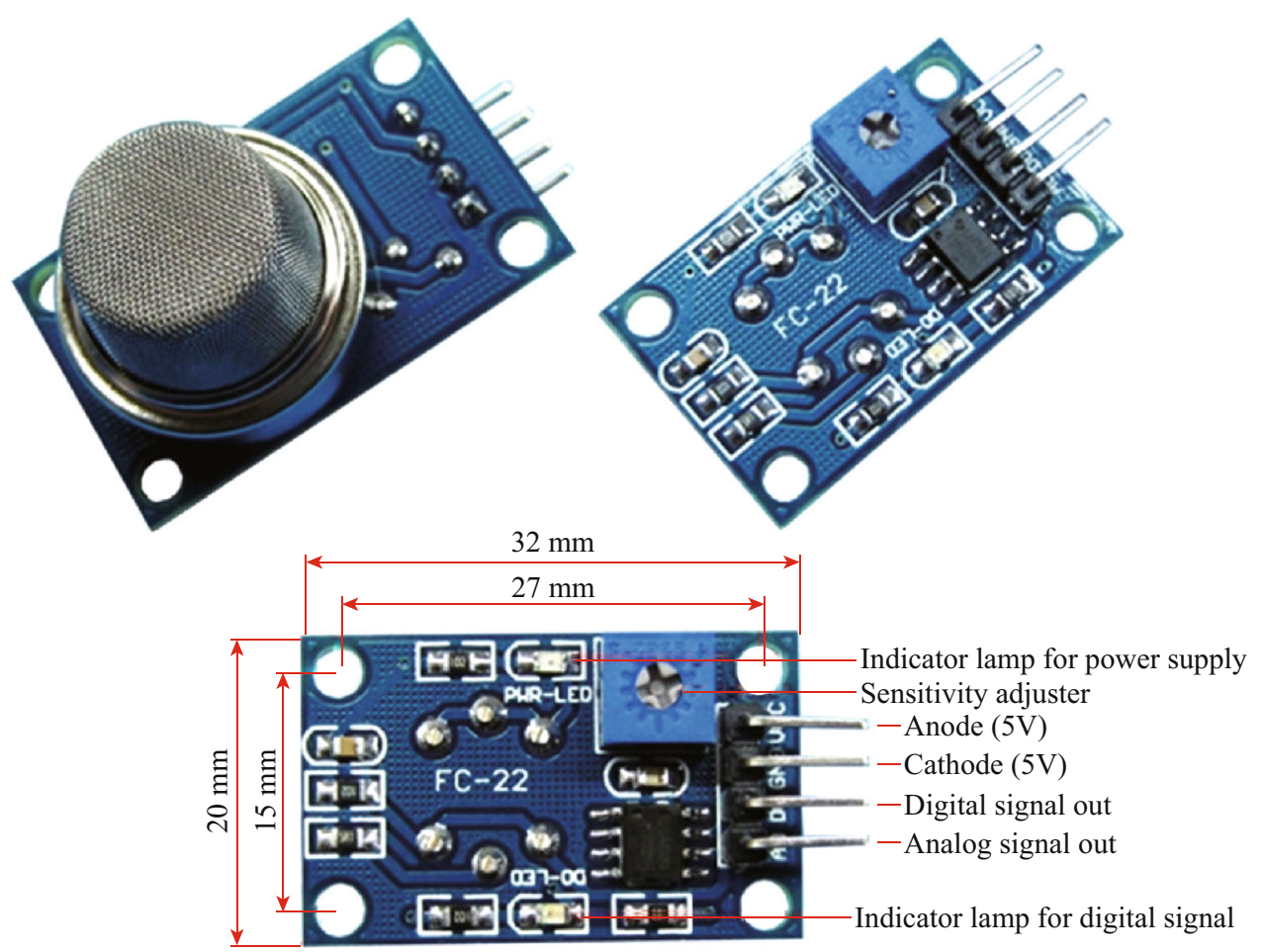

Fig. $1 \mathrm{SnO}_{2}$-based gas sensor for $\mathrm{CO}$ detection, product model: MQ-9

electric heating devices due to its excellent chemical stability at ambient temperature [16, 27]. All of these features for graphene are beneficial for its sensing properties, making it an ideal candidate for gas/vapor detecting. Therefore, great efforts have been put into the research of graphene-based gas/vapor sensors, leading to a giant leap in the development of graphene-based gas-sensing devices [24, 41-57]. We can clearly see that the number of published papers on graphene-based gas sensors has sharply increased over the period from 2007, as shown in Fig. 2. The first experiment focusing on the detection of gas molecules based on graphene was carried out in 2007 . Schedin et al. reported that micrometer-size sensors made from graphene were capable of detecting single gas molecules attached to or detached from graphene's surface, as depicted in Fig. 3 [24]. Their discovery indicated that graphene had a great potential for detecting and sensing.

In principle, a sensor is a device, purpose of which is to sense (i.e., to detect) some characteristics of its environs. It detects events or changes in quantities and provides a corresponding output, generally as an electrical or optical signal. According to different forms of reaction with external atmospheres, gas/vapor sensors can be classified into chemiresistor, silicon-based field-effect transistor (FET), capacitance sensor (CS), surface work function (SWF) change transistor, surface acoustic wave (SAW) change transistor, optical fiber sensor (OFS), and so on

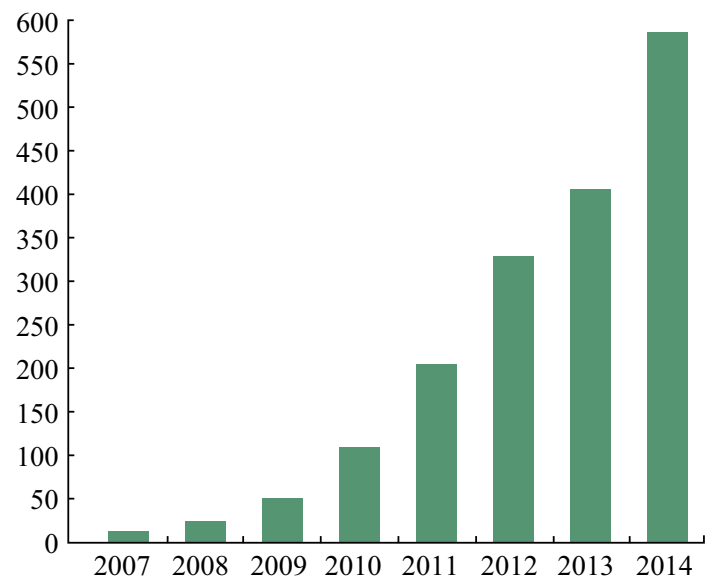

Fig. 2 Histogram detailing the number of graphene-based gas/vapor sensors publications per year for the period from 2007 to 2014 (data obtained from ISI Web of Knowledge, January 28, 2015)

[58]. Among them, chemiresistor is the most widely used in the construction of gas/vapor sensors and also the most popular product for practical applications, because of its long-history research, simple structure, convenience to implement, room-temperature operation, and relatively low cost $[59,60]$. Actually, we usually apply voltage on both electrodes of the device, and detect the current fluctuating over time when gas composition changes. Figure 4 

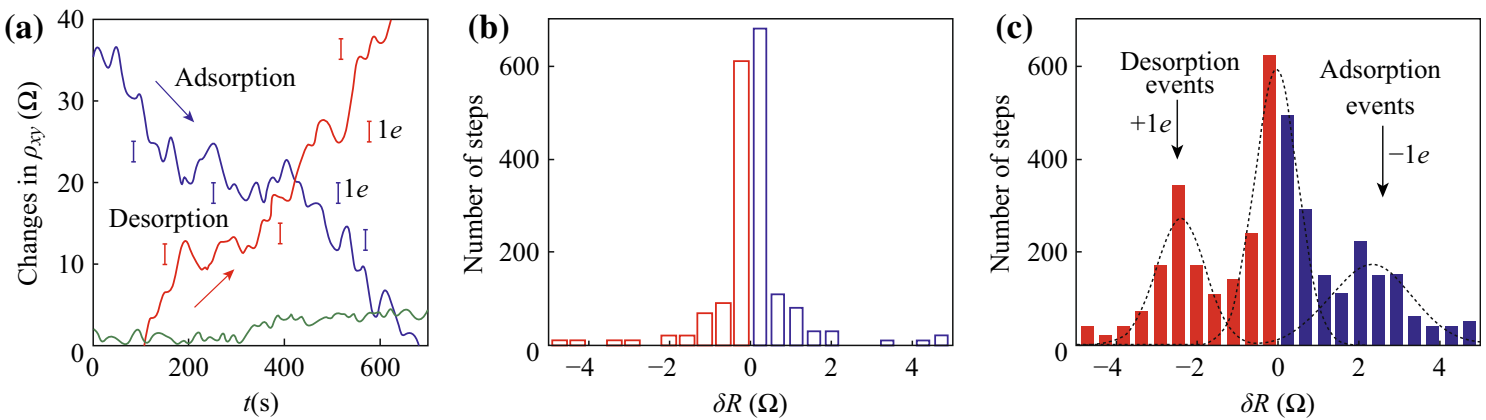

Fig. 3 Single-molecule detection. a Examples of changes in Hall resistivity observed near the neutrality point $\left(|n|<10^{11} \mathrm{~cm}^{-2}\right)$ during adsorption of strongly diluted $\mathrm{NO}_{2}$ (blue curve) and its desorption in vacuum at $50{ }^{\circ} \mathrm{C}$ (red curve). The green curve is a reference-the same device thoroughly annealed and then exposed to pure He. The curves are for a three-layered device in $B=10 \mathrm{~T}$. The grid lines correspond to changes in $\rho_{x y}$ caused by adding one electron charge, $e(\delta R \approx 2.5 \Omega)$, as calibrated in independent measurements by varying $V_{\mathrm{g}}$. For the blue curve, the device was exposed to $1 \mathrm{ppm}$ of $\mathrm{NO}_{2}$ leaking at a rate of $\approx 10^{-3} \Omega \mathrm{mbar} \mathrm{L} \mathrm{s}^{-1}$. Statistical distribution of step heights, $\mathrm{R}$, in this device without its exposure to $\mathrm{NO}_{2}$ (in helium) (b) and during a slow desorption of $\mathrm{NO}_{2}$ (c). For this analysis, all changes in $\rho_{x y}$ larger than $0.5 \Omega$ and quicker than $10 \mathrm{~s}$ (lock-in time constant was $1 \mathrm{~s}$ making the response time of $\approx 6 \mathrm{~s}$ ) were recorded as individual steps. The dotted curves in textbfc are automated Gaussian fits. Adapted from reference [24]. (Color figure online)

distinctly shows the typical structure of chemiresistors and silicon-based FET devices. An ordinary testing system for the research of gas sensors with chemiresistor structure is also displayed.

Through real-time monitoring and analyzing the response curves of sensing devices, the realistic realization of vapor detection can be achieved. Figure 5 is an example of real-time response of dimethyl methylphosphonate (DMMP) vapor monitored by para-phenylene diamine-reduced graphene oxide (PPD-RGO)-based vapor sensor. In Fig. 5, the excellent repeatability, low limit of detection, and superior selectivity of the vapor sensor have been distinctly displayed.

For evaluating the performance of gas/vapor sensors, there are a few critical parameters including component resistance, measure resistance, sensitivity, limit of detection, response time, recovery time, and selectivity. The definitions and formulas of these parameters are summarized in Table 1.

\section{Synthesis and Properties of Graphene}

There are mainly four approaches to synthesize singlelayered or few-layered graphene: micromechanical exfoliation, epitaxial growth, vapor deposition, and chemical reduction [64-67]. Novoselov et al. used scotch tapes to repeatedly peel flakes of graphite off the mesas which were fixed onto a $\mathrm{SiO}_{2} / \mathrm{Si}$ substrate, and the high-purity, singlelayered graphene was obtained [15]. By micromechanical exfoliation of highly ordered pyrolytic graphite, crystalline graphene nanosheets with large surface areas and a small number of layers could be obtained [65]. This method is very simple and does not need any special facilities. However, it is limited to laboratory research because of the small size and inefficiency of the production. Berger and his co-workers got graphene thin films which exhibited remarkable two-dimensional (2D) electron gas behaviors through thermal decomposition on the (0001) surface of $6 \mathrm{H}-\mathrm{SiC}$ [68]. Epitaxial growth, compared with mechanical exfoliation, can realize the preparation of graphene with larger sizes and higher qualities. Hence, this approach is of significant importance for graphene semiconductor devices. Although a great breakthrough has been made for this technique, there is still a long way to go toward mass production of the graphene with uniform thickness and acceptable cost. Chemical vapor deposition (CVD) is the most extensively used method in industrial manufacture considering the merits of controllable sizes and structures. By pyrolysis of carbon-containing compounds, graphene was grown on the surfaces of transition metals, such as $\mathrm{Cu}$ [36], Pt [69], Ni [37], Ru [70], and Ir [71]. Copper foil is the most common substrate material to build single-layered graphene. Li and his group have successfully synthesized large-area and uniform graphene films on copper foils with a high quality by CVD techniques using methane as carbon source [36].

In 2006, Stankovich et al. created a bottom-up approach when they incorporated graphene sheets in a composite material and the far-reaching method, which called chemical reduction of graphene oxide, pave the way for graphene's large-scale production, modification, and application [21]. Figure 6 displays the fabrication process flow of graphene-polymer composite. In 2009, Tung et al. reported a versatile solution-based process for the largescale production of single-layered chemically converted 

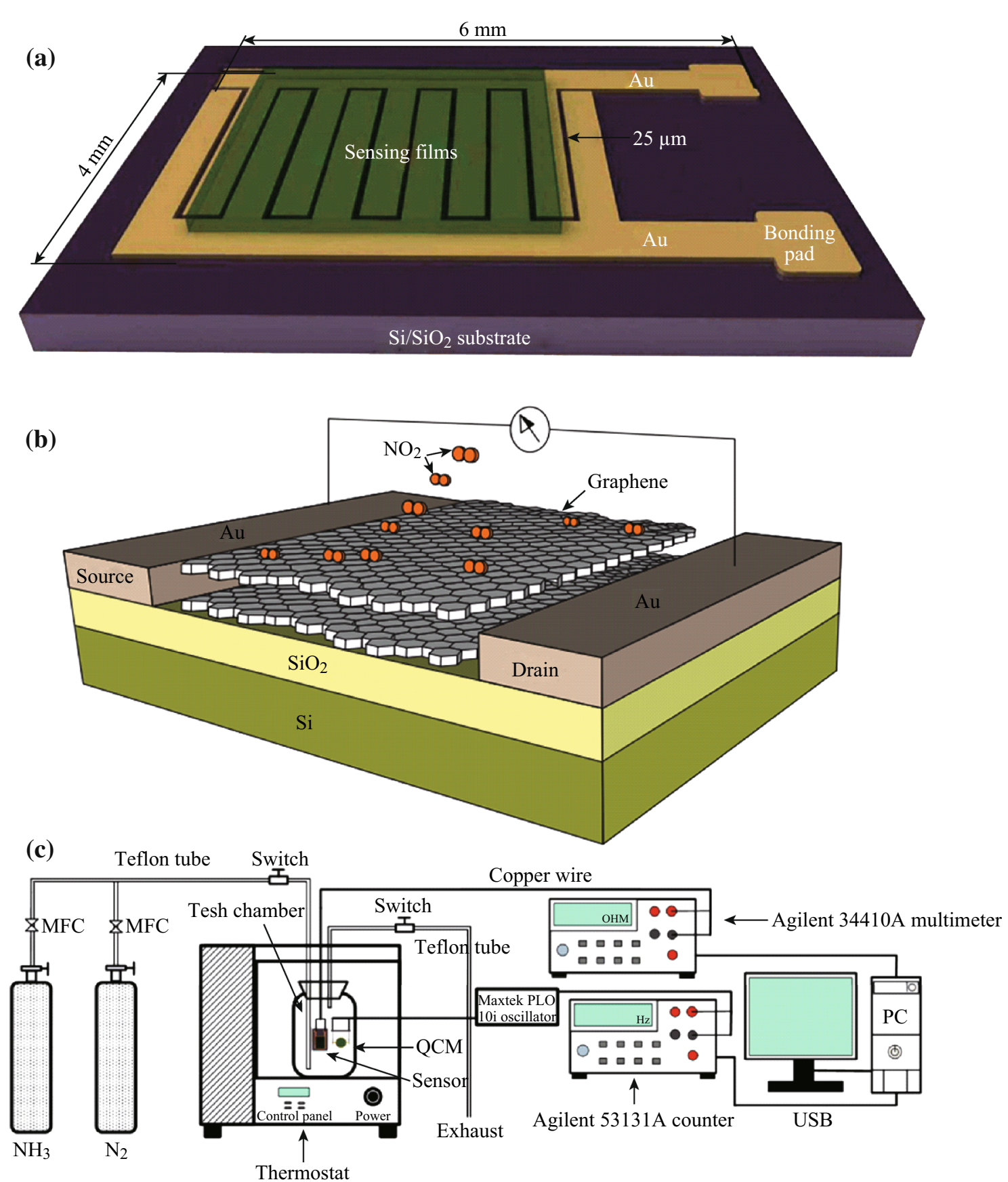

Fig. 4 Typical schematic diagram of a chemiresistor, b FET, and $\mathbf{c}$ testing system of gas sensors with chemiresistor structure. Adapted from reference $[61,62]$

graphene over the entire area of a silicon/ $\mathrm{SiO}_{2}$ wafer [72]. In general, there are three steps to obtain graphene-based composites: (1) strong oxidant, like $\mathrm{H}_{2} \mathrm{SO}_{4}, \mathrm{HNO}_{3}$, or $\mathrm{HClO}_{4}$, is used to transform graphite to graphite oxide. (2) complete exfoliation of graphite will take place, and molecular-level dispersion of individual graphene oxide (GO) in water or other polar solvent via ultrasonication will be achieved. (3) through the reduction of GO suspended in water or organic solvents, reduced graphene oxide (RGO) can be prepared without changing its morphology. Conductivity of RGO would be partly recovered too. The RGO sheets have quite high specific surface areas, which can be considered as a promising candidate for gas detection.

Brodie method [73], Staudenmaier method [74] and Hummers method [75] are three main ways to form GO. Hummers method is becoming the most popular approach to synthesize GO by virtue of its merits, including rapid, easy and relatively safe properties. Various modified 

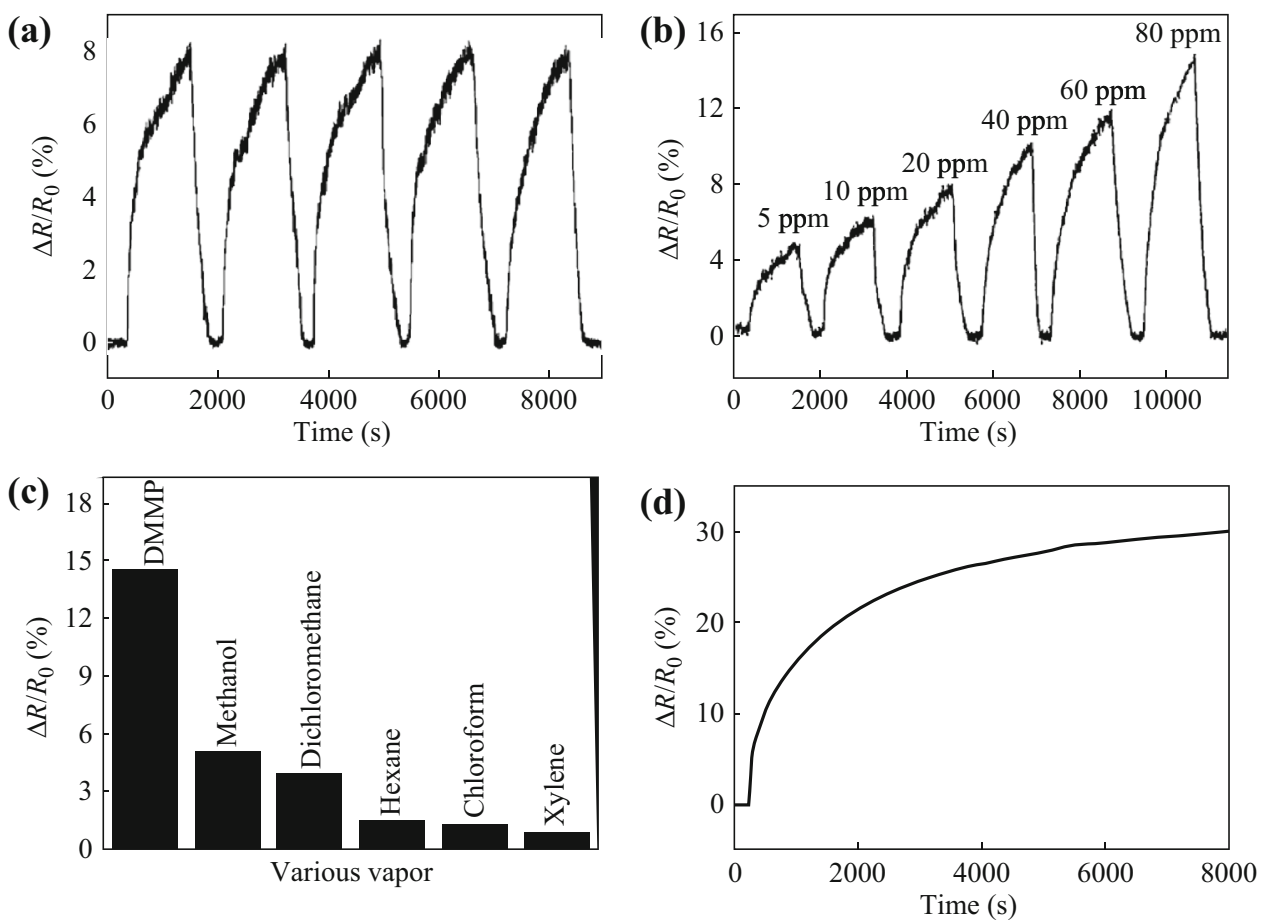

Fig. 5 a Reproducibility of response of the RGO sensor to 20 ppm DMMP vapor. b Response curve of the RGO sensor to DMMP vapor under the concentrations of 5-80 ppm. (c) Response of RGO sensor to DMMP compared with other analytes diluted to $5 \%$ of saturated vapor concentrations. d Response curve of the RGO sensor to DMMP vapor under the concentration of $80 \mathrm{ppm}$. Adapted from reference [63]

Table 1 Summary of the definition and formula of sensor parameters

\begin{tabular}{|c|c|c|}
\hline Parameter & Definition & Formula \\
\hline$R_{\mathrm{a}}$ & Resistance value of the device, when put into the dry, clean atmosphere & \\
\hline$R_{\mathrm{g}}$ & Resistance value of the device, when put into gas to be detected & \\
\hline$S$ & Ratio of variation of resistance $\left(\left|R_{\mathrm{a}}-R_{\mathrm{g}}\right|\right)$ to initial resistance $\left(R_{\mathrm{a}}\right)$ & $S=\left|\frac{\Delta R}{R_{\mathrm{a}}}\right| \times 100 \%=\left|\frac{R_{\mathrm{a}}-R_{\mathrm{g}}}{R_{\mathrm{a}}}\right| \times 100 \%$ \\
\hline LOD & $\begin{array}{l}\text { The lowest concentration of target gas that can be distinguished from the common } \\
\text { atmosphere, which produces a signal greater than three times the standard deviation of the } \\
\text { noise level }\end{array}$ & \\
\hline$T_{\text {res }}$ & $\begin{array}{l}\text { Period of time from gas sensor contact with gas to be detected to variation of resistance reach } \\
\text { to } 90 \% \text { of }\left|R_{\mathrm{a}}-R_{\mathrm{g}}\right|\end{array}$ & \\
\hline$T_{\text {rec }}$ & $\begin{array}{l}\text { Period of time from gas sensor away from gas to be detected to variation of resistance reach } \\
\text { to } 90 \% \text { of }\left|R_{\mathrm{a}}-R_{\mathrm{g}}\right|\end{array}$ & \\
\hline$D$ & Ratio of response of target gas $\left(S_{c}\right)$ to response of disturbed gas $\left(S_{i}\right)$. & $D=\frac{S_{c}}{S_{i}}$ \\
\hline
\end{tabular}

Hummers methods have been reported to promote the progress of GO preparation [76-79].

In a sense, the development of chemical reduction can provide equivalent routes for production and modification of graphene materials via wet chemical techniques. As such, the reductant is so important since it can affect the properties of vapor detecting devices to a large degree [80111]. Fan and co-workers observed that a stable graphene suspension could be quickly prepared by simply heating an exfoliated-GO suspension under strongly alkaline conditions at moderate temperatures $\left(50-90^{\circ} \mathrm{C}\right)$. This interesting reaction provides a green route to the synthesis of graphene with excellent dispersibility in water [81]. Zhu and his team developed a green and facile approach to synthesize chemically converted graphene nanosheets (GNS) through reducing exfoliated GO precursors by reducing sugars, such as glucose, fructose, and sucrose. Their unremitting efforts pave a new way to enlarge the production of widely used GNS with a high quality [95]. Recently, Liu et al. had demonstrated a green and facile 

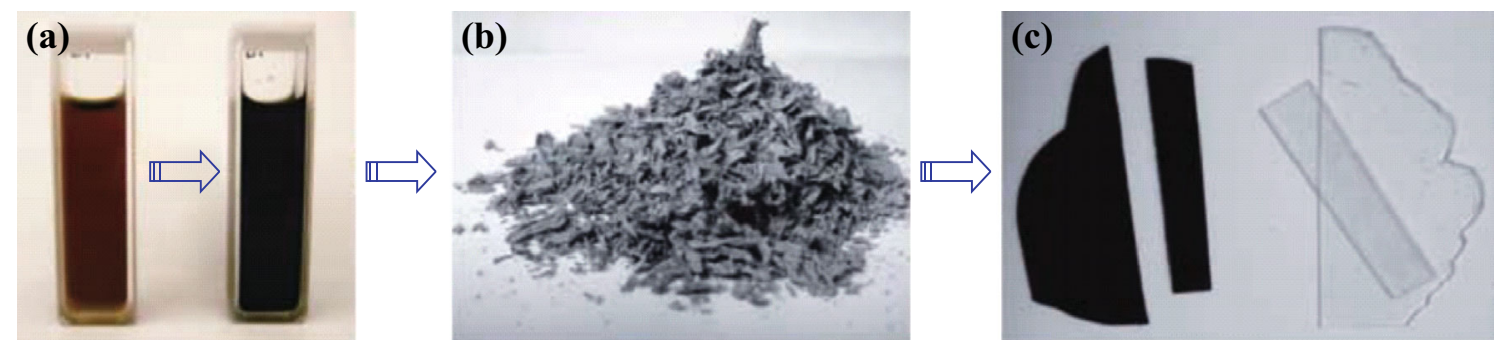

Fig. 6 a Suspensions of phenyl isocyanate-treated graphite oxide $\left(1 \mathrm{mg} \mathrm{mL}^{-1}\right)$ and dissolved polystyrene in DMF before (left) and after (right) reduction by $\mathrm{N}, \mathrm{N}$-dimethylhydrazine. b Composite powders as obtained after coagulation in methanol. c Hot-pressed composite $(0.12$ vol\% of graphene) and pure polystyrene of the same 0.4-mm thickness and processed in the same way. Adapted from reference [21]

approach to synthesize RGO through reduction of GO by $\mathrm{Zn}$ powder under acidic condition at room temperature. This approach offers a possibility for the production of RGO with cost-effective, environment-friendly and largescale characteristics [106].

Recently, we found that PPD-reduced RGO exposed to DMMP exhibited much better response than that of the RGO reduced from hydrazine [63]. At the same time, we confirmed that RGO reduced from aniline exhibited a better response to ammonia, compared with the RGO reduced from hydrazine [107]. The sensing properties of aniline-reduced graphene attached with different states of polyaniline (PANI) had also been studied. The results suggested that free RGO exhibited better response to $\mathrm{NH}_{3}$ and showed higher sensitivity with concentrations at ppm levels compared to those of the RGO attached with aciddoped PANI and de-doped PANI [108].

\section{Properties of Gas/Vapor Sensors}

Graphene has shown excellent sensing properties toward $\mathrm{NH}_{3}, \mathrm{NO}_{2}, \mathrm{H}_{2}, \mathrm{CO}, \mathrm{SO}_{2}, \mathrm{H}_{2} \mathrm{~S}$, and volatile organic compounds (VOCs). Subsequently, some information from related works was summarized and discussed. Efforts have been made to exploit these sensitivities in the development of new sensor technologies.

\subsection{Ammonia Detection}

Ammonia $\left(\mathrm{NH}_{3}\right)$ is a compound of nitrogen and hydrogen with the formula $\mathrm{NH}_{3}$, which is a colorless gas with a characteristic pungent smell. Ammonia not only contributes significantly to the nutritional needs of terrestrial organisms by serving as a precursor to food and fertilizers, but also is a building-block for the synthesis of many pharmaceuticals, and is used in many commercial products. Although widely used, this gas is both caustic and hazardous, and thus it is harmful to human and would pollute environment. Therefore, the detection of $\mathrm{NH}_{3}$ is a pressing requirement for the modern society.

Recently, a great deal of efforts had presented a great leap forward in the development of graphene gas sensors for ammonia detection. Gautam and his team investigated ammonia gas-sensing behaviors of graphene synthesized by CVD, of which the sensitivity and the recovery time were enhanced by the deposition of gold nanoparticles on the surface of graphene films [112]. Yavari et al. manufactured a device which was distinctly superior to commercially available $\mathrm{NO}_{2}$ and $\mathrm{NH}_{3}$ detectors [113]. They found graphene films synthesized by CVD (as displayed in Fig. 7) had an outstanding property of detection of $\mathrm{NO}_{2}$ and $\mathrm{NH}_{3}$ at room temperature. The detection limits of both $\mathrm{NO}_{2}$ and $\mathrm{NH}_{3}$ reached to ppb level. Wu and his co-workers reported a contrast experiment between graphene/PANI nanocomposites, and PANI to explore their sensing

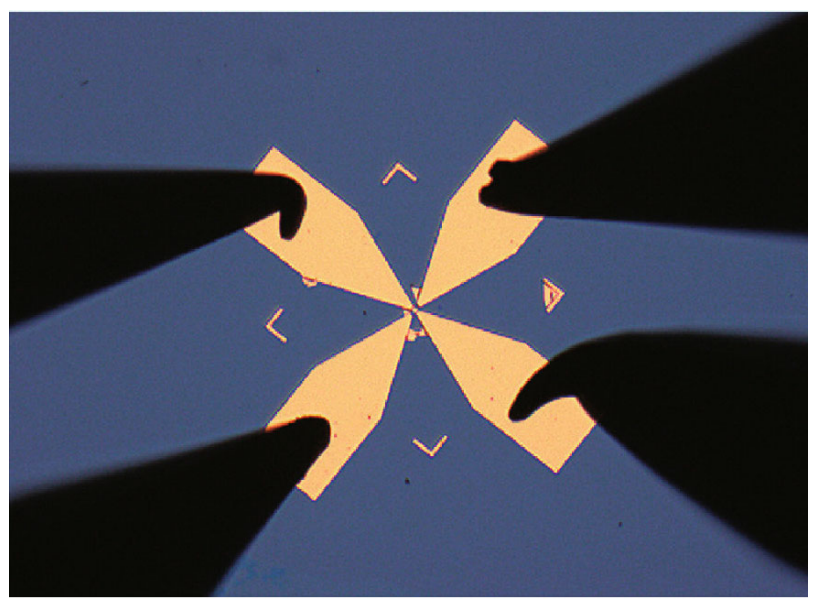

Fig. 7 Optical micrographs of graphene film grown by $\mathrm{CVD}$ on $\mathrm{Cu}$ and then transferred onto a $\mathrm{Si} / \mathrm{SiO}_{2}$ substrate. Gold contact pads in the Van Der Pauw configuration were deposited on the film. Adapted from reference [113] 
properties [61]. The results indicated that the $\mathrm{NH}_{3}$ detection limit of graphene/PANI sensors (ca. 1 ppm) was lower than that of PANI (ca. $10 \mathrm{ppm}$ ). This indicated that the sensitivity of graphene/PANI sensors for $\mathrm{NH}_{3}$ detection was enhanced by introduction of graphene into PANI. A simple, low-cost, and practical inkjet-printing technique for fabricating an innovative flexible gas sensor based on graphene-poly (3, 4-ethylenedioxythiophene):poly (styrene sulfonate) (PEDOT:PSS) composite films with high uniformity over a large area was created by Seekaew et al. [114]. Figure 8 clearly depicts a schematic diagram of this brand new gas sensor fabrication process. The ink-jet printed graphene-PEDOT: PSS gas sensor exhibited high response and high selectivity to $\mathrm{NH}_{3}$ in a low concentration ranging from 25 to $1000 \mathrm{ppm}$ at room temperature. This novel and convenient method would provide a new thought for the controllable and mass manufacture of gas detectors. Table 2 summarized recent researches about $\mathrm{NH}_{3}$ detection based on graphene.

\subsection{Nitrogen Dioxide Detection}

Nitrogen dioxide is one of several nitrogen oxides with the formula $\mathrm{NO}_{2}$. On one hand, this reddish-brown gas, as one kind of the important chemical feedstocks, is an intermediate in the industrial synthesis of nitric acid. On the other hand, the toxic gas has characteristic sharp, biting odor, and is a prominent air pollutant. The whole society has a strong demand for $\mathrm{NO}_{2}$ detection, in order to curb environmental pollution and keep the safety and health of human beings.

Compared to the development of ammonia detection, there are several reports about $\mathrm{NO}_{2}$ sensing showing the lower detection limit, higher response, and more practical manufacturing techniques. Choi and his co-workers reported a highly sensing $\mathrm{NO}_{2}$ gas sensor based on multilayered graphene films synthesized by a CVD method on a microheater-embedded flexible substrate [124]. The multilayered graphene had a very low detection limit of $\mathrm{NO}_{2}$ at sub-ppm $(<200 \mathrm{ppb})$ levels. It also presented high responses and a short response time, when it was exposed to $1 \mathrm{ppm} \mathrm{NO}_{2}$ at room temperature. Hoa et al. reported that they built a gas sensor with hybrid structures of $2 \mathrm{D}$ graphene and 2D NiO nanosheets, sensitivity of which was two orders higher than those of devices based on $\mathrm{NiO}$ nanosheets alone toward $\mathrm{NO}_{2}$ even at 1 ppm level [125]. As shown in Fig. 9, the detector had excellent sensing properties, such as high sensitivity and superior selectivity. Nanosphere-like $\alpha$ - $\mathrm{Fe}_{2} \mathrm{O}_{3}$-modified RGO nanosheets were prepared by Dong's team [109]. The 3D-structured nanocomposites exhibited a very high response of $150.63 \%$ to $90 \mathrm{ppm} \mathrm{NO}_{2}$ at room temperature, which was

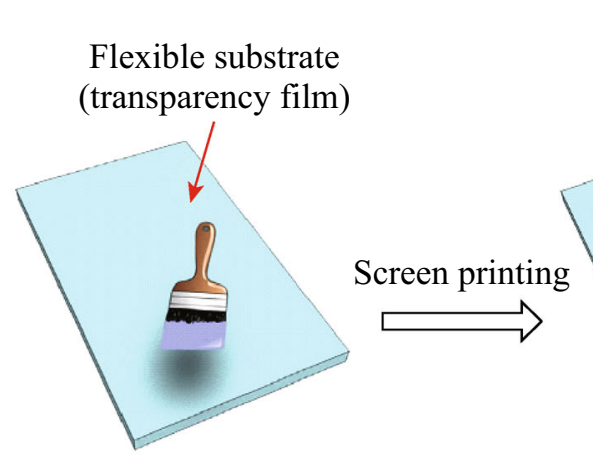

(a) Prepared interdigitated electrode

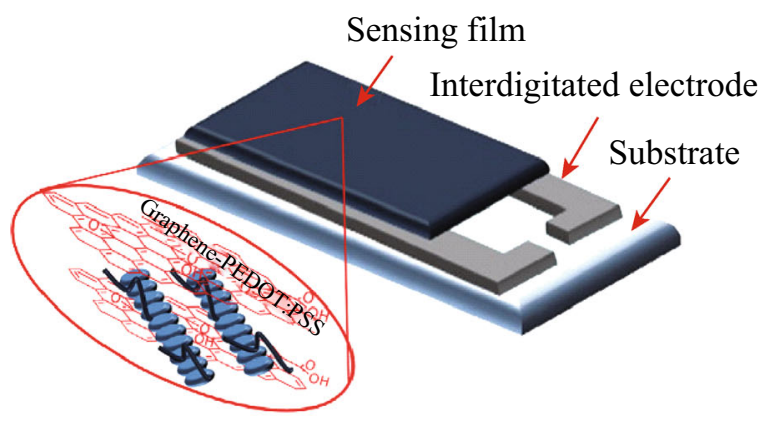

(c) Schematic diagram of gas sensor

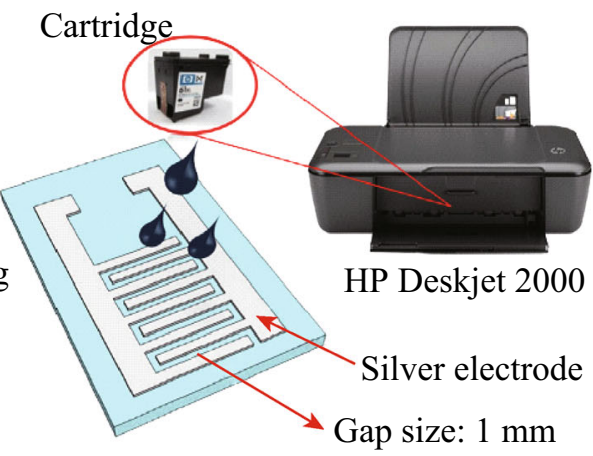

(b) Ink-jet printing

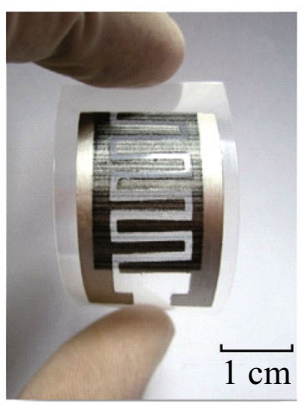

(d) Photograph of sensor device

Fig. 8 Schematic diagram of gas-sensor fabrication process. Adapted from reference [114] 
Table 2 A summary of recent researches about graphene-based gas sensors for $\mathrm{NH}_{3}$ detection at room temperature

\begin{tabular}{|c|c|c|c|c|c|c|}
\hline Sensing material & Structure of sensor & Target gas & $T_{\mathrm{res}}(\mathrm{s})$ & LOD & $T_{\mathrm{rec}}(\mathrm{s})$ & Ref. \\
\hline $\mathrm{RGO} / \mathrm{MnO}_{2}+\mathrm{PANI}$ & Chemiresistor & $\mathrm{NH}_{3}$ & 1080 & $25 \% / 5 \mathrm{ppm}$ & 240 & [115] \\
\hline RGO/ANI & Chemiresistor & $\mathrm{NH}_{3}$ & 1080 & $10.7 \% / 5 \mathrm{ppm}$ & 170 & [107] \\
\hline RGO/ANI + PANI & Chemiresistor & $\mathrm{NH}_{3}$ & 1080 & $20 \% / 20 \mathrm{ppm}$ & 120 & [108] \\
\hline RGO/Py & Chemiresistor & $\mathrm{NH}_{3}$ & 1.4 & $2.4 \% / 1 \mathrm{ppb}$ & 76 & [116] \\
\hline RGO/Py & Chemiresistor & $\mathrm{NH}_{3}$ & 720 & $4.2 \% / 50 \mathrm{ppb}$ & 375 & [117] \\
\hline $\mathrm{GR}+\mathrm{Au}$ & Chemiresistor & $\mathrm{NH}_{3}$ & 1200 & $1 \% / 6 \mathrm{ppm}$ & 3800 & [112] \\
\hline GR & FET & $\mathrm{NH}_{3}$ & - & $0.49 \mathrm{~V} / \mathrm{ppm}$ & - & [118] \\
\hline GR & Chemiresistor & $\mathrm{NH}_{3}$ & 21,600 & $3 \% / 500 \mathrm{ppb}$ & 21,600 & [113] \\
\hline GR + PANI & Chemiresistor & $\mathrm{NH}_{3}$ & 50 & $0.7 \% / 1 \mathrm{ppm}$ & 23 & {$[61]$} \\
\hline GR supported by mica substrate & FET & $\mathrm{NH}_{3}$ & 60 & $4 \% / 50 \mathrm{ppm}$ & - & [119] \\
\hline GR gated by ionic liquid & FET & $\mathrm{NH}_{3}$ & 33 & $130 \mathrm{ppb}$ & - & [120] \\
\hline Printed GR + PEDOT:PSS & Chemiresistor & $\mathrm{NH}_{3}$ & 180 & $25 \mathrm{ppm}$ & 300 & [114] \\
\hline $\mathrm{RGO}+\mathrm{P} 3 \mathrm{HT}$ & Chemiresistor & $\mathrm{NH}_{3}$ & 141 & $7.15 \% / 10 \mathrm{ppm}$ & 488 & {$[121]$} \\
\hline RGO/Tannic acid & Chemiresistor & $\mathrm{NH}_{3}$ & 40 & $9.3 \% / 1310 \mathrm{ppm}$ & 170 & {$[122]$} \\
\hline $\mathrm{RGO} / \mathrm{Cu}(\mathrm{OH})_{4}^{2-}+\mathrm{Cu}_{2} \mathrm{O}$ & Chemiresistor & $\mathrm{NH}_{3}$ & 28 & $80 \% / 100 \mathrm{ppm}$ & 206 & {$[123]$} \\
\hline
\end{tabular}

$R G O$ reduced graphene oxide, $G R$ Graphene, $P P D$ p-phenyldiamine, $D M M P$ dimethyl methyl phosphonate, $P A N I$ polyaniline, $A N I$ aniline, $P y$ pyrrole, $C O P$ Chemical oxidative polymerization
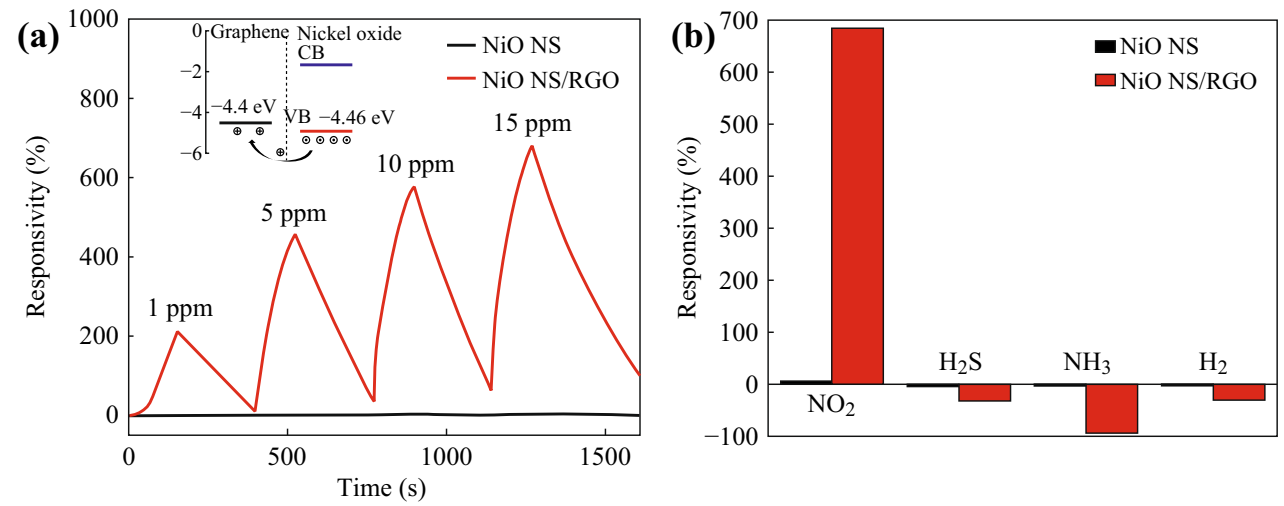

Fig. 9 a Response of $\mathrm{NiO}$ nanosheet-based and $\mathrm{NiO}$ nanosheet/RGO-based gas sensors in various $\mathrm{NO}_{2}$ concentrations at $200{ }^{\circ} \mathrm{C}$. b Response of $\mathrm{NiO}$ nanosheet-based and $\mathrm{NiO}$ nanosheet/RGO-based gas sensors in various gases, where the concentrations of $\mathrm{NO}_{2}, \mathrm{H}_{2} \mathrm{~S}$, and $\mathrm{NH}_{3}$ were $100 \mathrm{ppm}$, and $\mathrm{H}_{2}$ was $4 \%$. Adapted from reference [125]

65.5 times higher than that of pure graphene, and the detection limit could be decreased down to $0.18 \mathrm{ppm}$. Huang et al. fabricated a gravure-printed chemiresistortype $\mathrm{NO}_{2}$ sensor based on sulfonated RGO decorated with $\mathrm{Ag}$ nanoparticles ( $\mathrm{RGO} / \mathrm{S}+\mathrm{Ag}$ ) (as depicted in Fig. 10) [126]. Compared with other graphene-based sensors, this device showed more rapid response to $\mathrm{NO}_{2}$. When exposed to $50 \mathrm{ppm} \mathrm{NO}_{2}$, the sensor exhibited a sensitivity of $74.6 \%$, a response time of $12 \mathrm{~s}$, and a recovery time of 20 s. Recently, Ju et al. reported a bendable and washable electronic textile (e-textile) gas sensors composed of reduced graphene oxides using commercially available yarns and molecular glues through an electrostatic selfassembly method [127]. The resultant e-textile gas sensor possessed the following features: (1) chemical durability to several detergents washing treatments, (2) mechanical stability under 1000 bending tests at an extreme bending radius of $1 \mathrm{~mm}$, and (3) a high response to $\mathrm{NO}_{2}$ gas at room temperature with selectivity to other gases such as acetone, ethanol, ethylene, and $\mathrm{CO}_{2}$. Herein, we summarized recent researches about graphene-based gas sensors for $\mathrm{NO}_{2}$ detection, as shown in Table 3.

\subsection{Hydrogen Detection}

While hydrogen $\left(\mathrm{H}_{2}\right)$ is not very reactive under standard conditions, it does form compounds with most elements. As one of the most important industrial chemicals and 


\section{(a)}

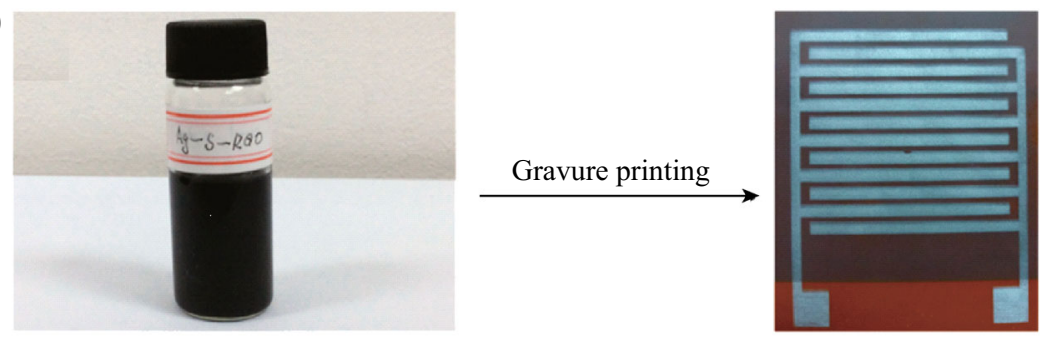

(b)

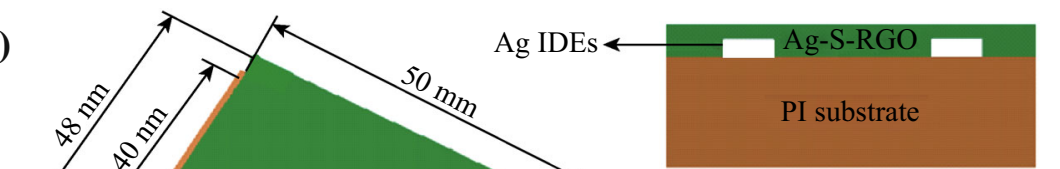

Fig. 10 a Photographs of RGO/S + Ag ink and sensing layer printed onto the PI substrate with Ag-IDEs, respectively. b Schematic of the printed $\mathrm{RGO} / \mathrm{S}+\mathrm{Ag}$ sensor. Adapted from reference [126]

Table 3 A summary of recent researches about graphene-based gas sensors for $\mathrm{NO}_{2}$ detection at room temperature

\begin{tabular}{|c|c|c|c|c|c|c|}
\hline Sensing material & Structure of sensor & Target gas & $T_{\text {res }}(\mathrm{s})$ & LOD & $T_{\text {rec }}(\mathrm{s})$ & Ref. \\
\hline GR & Chemiresistor & $\mathrm{NO}_{2}$ & 3000 & $4 \% / 100 \mathrm{ppb}$ & 3000 & [113] \\
\hline Single-layered GR & FET & $\mathrm{NO}_{2}$ & 3600 & $2.5 \mathrm{ppm}$ & - & [128] \\
\hline Ozone-treated GR & Chemiresistor & $\mathrm{NO}_{2}$ & 900 & $1.3 \mathrm{ppb}$ & 1800 & [129] \\
\hline GR/PMMA on a flexible PET substrate & Chemiresistor & $\mathrm{NO}_{2}$ & 170 & $25 \% / 200 \mathrm{ppm}$ & - & {$[130]$} \\
\hline $\mathrm{RGO} /$ hydrazine $+\mathrm{WO}_{3}$ & Chemiresistor & $\mathrm{NO}_{2}$ & - & $5 \mathrm{ppm}$ & - & [131] \\
\hline Multilayered GR & Chemiresistor & $\mathrm{NO}_{2}$ & 1800 & $6 \% / 1 \mathrm{ppm}$ & - & [124] \\
\hline $\mathrm{RGO}+\mathrm{NiO}$ & Chemiresistor & $\mathrm{NO}_{2}$ & 125 & $200 \% / 1 \mathrm{ppm}\left(200^{\circ} \mathrm{C}\right)$ & 250 & {$[125]$} \\
\hline Bilayer GR & FET & $\mathrm{NO}_{2}$ & - & Establish a theoretical model & - & {$[62]$} \\
\hline $\mathrm{RGO} / \mathrm{FeCl}_{3}+\alpha-\mathrm{Fe}_{2} \mathrm{O}_{3}$ & Chemiresistor & $\mathrm{NO}_{2}$ & 80 & $180 \mathrm{ppb}$ & 44 & [109] \\
\hline $\mathrm{RGO}+\mathrm{PVP}$ & QCM & $\mathrm{NO}_{2}$ & - & $20 \mathrm{ppm}$ & - & {$[132]$} \\
\hline Printed $\mathrm{RGO} / \mathrm{S}+\mathrm{Ag}$ & Chemiresistor & $\mathrm{NO}_{2}$ & 12 & $74.6 \% / 50 \mathrm{ppm}$ & 20 & [126] \\
\hline RGO/hydrazine $+\mathrm{ZnO}$ & Chemiresistor & $\mathrm{NO}_{2}$ & 165 & $25.6 \% / 5 \mathrm{ppm}$ & 499 & {$[133]$} \\
\hline $\mathrm{RGO}+\mathrm{SnO}_{2}$ aerogel & Chemiresistor & $\mathrm{NO}_{2}$ & 190 & $50 \mathrm{ppm}$ & 224 & [134] \\
\hline $\mathrm{GO}+\mathrm{Cs}$ & Chemiresistor & $\mathrm{NO}_{2}$ & 240 & $90 \mathrm{ppb}$ & 540 & {$[135]$} \\
\hline $\mathrm{RGO} / \mathrm{NaBH}_{4}$ & Chemiresistor & $\mathrm{NO}_{2}$ & 420 & $11.5 \% / 5 \mathrm{ppm}$ & 1680 & [136] \\
\hline $\mathrm{RGO}+\mathrm{SnO}_{2}$ & Chemiresistor & $\mathrm{NO}_{2}$ & 75 & $3.31 \% / 5 \mathrm{ppm}\left(50^{\circ} \mathrm{C}\right)$ & 300 & {$[137]$} \\
\hline $\mathrm{RGO} / \mathrm{WO}_{3}$ & Chemiresistor & $\mathrm{NO}_{2}$ & 540 & $769 \% / 5 \mathrm{ppm}$ & 1080 & {$[138]$} \\
\hline $\mathrm{RGO} / \mathrm{In}_{2} \mathrm{O}_{3}$ & Chemiresistor & $\mathrm{NO}_{2}$ & 240 & $8.25 / 30 \mathrm{ppm}$ & 1440 & [139] \\
\hline
\end{tabular}

$R G O$ reduced graphene oxide, $G O$ Graphene oxide, GR Graphene, $P V P$ Polyvinylpyrrolidone, $Q C M$ quartz crystal microbalance

potential clean energy facing the future, hydrogen has aroused a great attention. Large-scale preparation, transportation, and application of this material have a strong demand for rapid detection and accurate analysis, which makes $\mathrm{H}_{2}$ detection become a research hotspot recent years.

Johnson and his co-workers reported a novel Pd-functionalized multilayered graphene nanoribbon networks 
with excellent sensitivity to $\mathrm{H}_{2}$ at ppm levels. The fluffy porous material structure and noble metal modification accounted for their fast response and recovery time at room temperature [140]. The relationship between the sensor performance and work temperature was studied as well. Their work offers the possibility of using functionalized graphene-based nanoribbon networks in a wide range of gas/vapor-sensing applications. Figure 11 shows the response of the device varying with the concentration of $\mathrm{H}_{2}$ and work temperature. The real-time response curves of the detector as well as the activation energy of hydrogen detection at background temperatures varied from room temperature to $175{ }^{\circ} \mathrm{C}$ were measured by $\mathrm{Chu}$ et al. [141]. Three $E_{\mathrm{a}}$ (activation energy) were observed dependent on the background temperature: $0.832 \mathrm{eV}$ for $30-60{ }^{\circ} \mathrm{C}$, $0.396 \mathrm{eV}$ for $60-100{ }^{\circ} \mathrm{C}$, and $0.057 \mathrm{eV}$ for $100-170{ }^{\circ} \mathrm{C}$. Their results contribute to the theoretical research of gas/vapor detection. Meanwhile, Chu and his team studied the effect of thickness of the Pt metal layer on hydrogensensing sensitivity of Pt-coated and multilayered graphene, and they concluded that the Pt coating improved the response time of the graphene sensor, but decreased the sensitivity [142]. When the thickness of the Pt metal layer was about $1 \mathrm{~nm}$, the sensor presented the highest sensitivity. Mehta and co-workers had successfully fabricated a device with ultrafast response and recovery of hydrogen sensing based on graphene composite layers with $\mathrm{Pd}$ and $\mathrm{Pt}$ nanoparticles dispersed on graphene layers [143]. Jiang et al. considered the dissociative adsorption of $\mathrm{H}_{2}$ molecules on graphene with mono-atom-vacancies by using density functional theory (DFT) calculations [144]. They demonstrated that this defected graphene was promising for ultrasensitive room-temperature hydrogen sensing and the LOD could even reach to $10^{-35} \mathrm{~mol} \mathrm{~L}^{-1}$ theoretically. The reaction pathway of $\mathrm{H}_{2}$ molecule dissociative adsorption on pristine graphene and treated graphene with a monoatom-vacancy was displayed in Fig. 12. Table 4 summarized recent researches about $\mathrm{H}_{2}$ detection based on graphene.

\subsection{Carbon Dioxide, Carbon Monoxide, and Methane Detection}

Carbon dioxide $\left(\mathrm{CO}_{2}\right)$, carbon monoxide $(\mathrm{CO})$, and methane $\left(\mathrm{CH}_{4}\right)$ are very familiar to our daily life, industrial manufacture, and environmental protection. $\mathrm{CO}_{2}$ is not only the primary source of carbon in life, but also of significant impact in air pollution, which can cause global warming. $\mathrm{CO}$ is toxic to humans when encountered in concentrations above about $35 \mathrm{ppm}$. Besides, this colorless, odorless, and tasteless gas is one kind of gaseous fuels, which is widely used as reducing agent in industry. $\mathrm{CH}_{4}$ is the simplest alkane and the main component of natural gases. On one hand, the relative abundance of methane makes it an attractive fuel. On the other hand, it is the chief culprit of a gas explosion. In a word, detection and early warning of these gases is a pressing need for modern society.

Nemade et al. have carried out a lot of work focusing on graphene-based carbon dioxide sensor over the recent years [158]. They fabricated a device with excellent stability, short response and recovery times, and low detection limit based on few-layered graphene synthesized by an electrochemical exfoliation method. It is worth mentioning that this few-layered graphene also showed remarkable sensing features to liquid petroleum gases, which endowed it with a giant potential application. In addition, they investigated the sensing characteristic to $\mathrm{CO}_{2}$ of graphene/ $\mathrm{Y}_{2} \mathrm{O}_{3}$ quantum dots (QDs) [159], graphene/ $\mathrm{Sb}_{2} \mathrm{O}_{3}$ QDs [160], and graphene $/ \mathrm{Al}_{2} \mathrm{O}_{3}$ QDs [161], respectively. The experimental results showed that gas-sensing properties could be changed by different combination of materials. Liu and his team
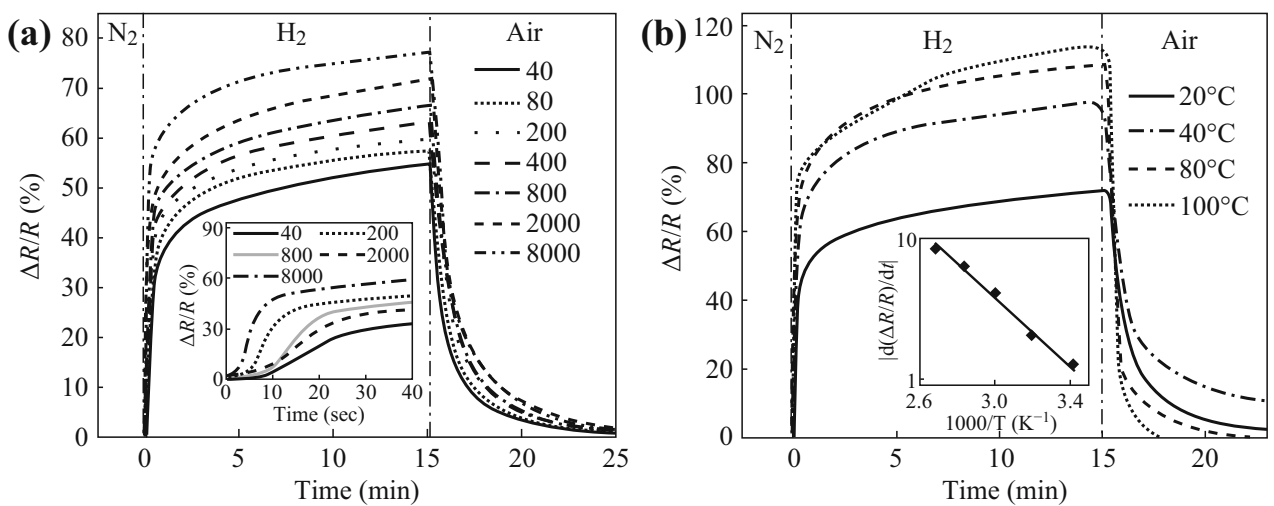

Fig. 11 a The responses of the Pd-functionalized MLGN network sensor as a function of time when it is exposed to different concentrations of $\mathrm{H}_{2}$ in $\mathrm{N}_{2}$ ranging from 40 to $8000 \mathrm{ppm}$. b The response as a function of operating temperature in the range $20-100{ }^{\circ} \mathrm{C}$ for the MLGN network sensor when exposed to $2000 \mathrm{ppm}_{2}$. Adapted from reference [140] 

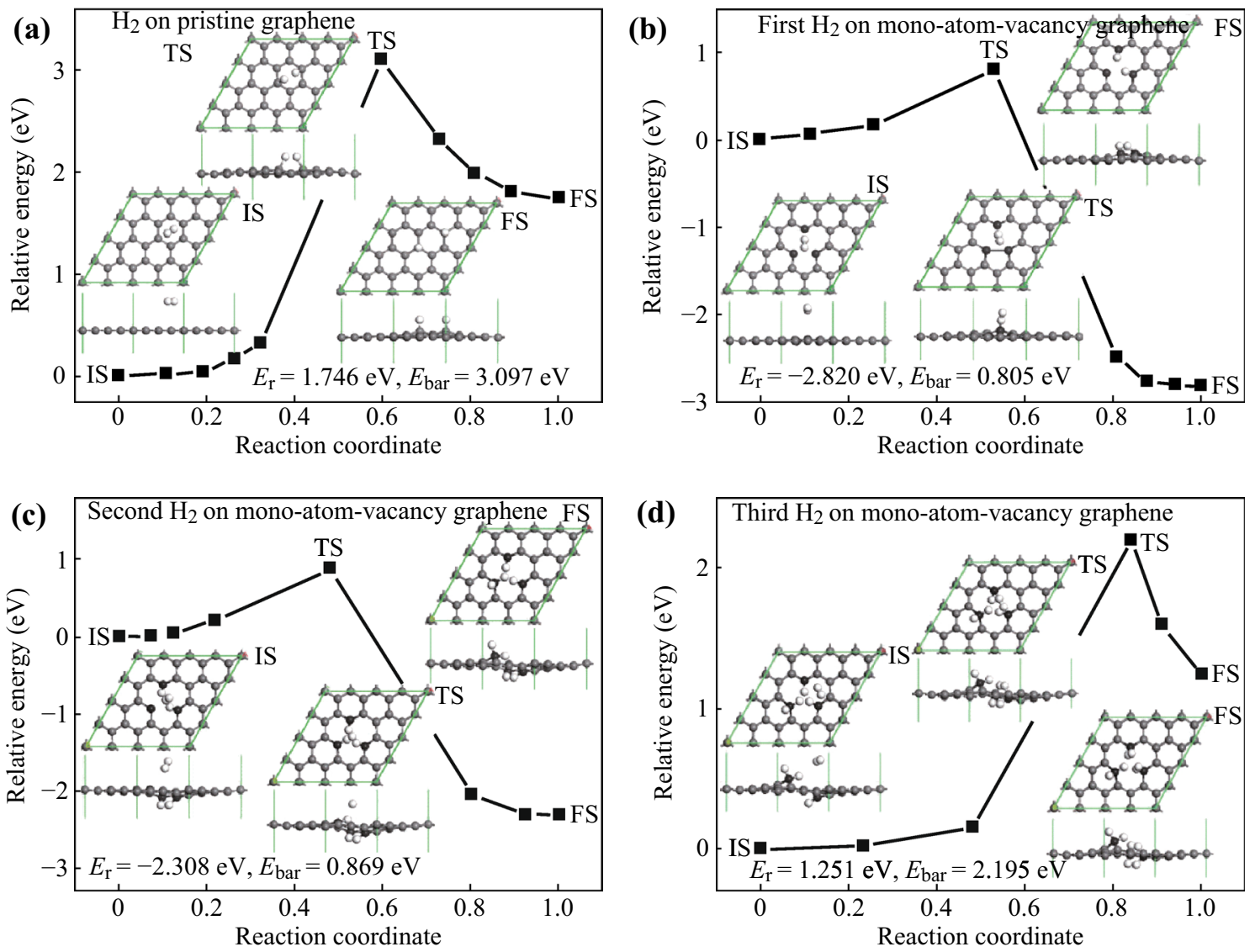

Fig. 12 The reaction pathways of $\mathrm{H}_{2}$ molecule dissociative adsorption on pristine graphene (a), and on graphene with a mono-atom-vacancy for the first $\mathrm{H}_{2}$ molecule (b), the second $\mathrm{H}_{2}$ molecule (c), and the third $\mathrm{H}_{2}$ molecule (d). IS, TS, and FS represent initial structure, transition structure, and final structure, respectively. Their atomic structures are shown in the inserts. The energy of the IS is taken to be zero. The units of $E_{\mathrm{bar}}$ and $E_{\mathrm{r}}$ are $\mathrm{eV}$, where $E_{\mathrm{bar}}$ is the energy barrier, and $E_{\mathrm{r}}$ is the reaction energy. The gray, black, and white atoms are saturated $\mathrm{C}$, unsaturated $\mathrm{C}$, and $\mathrm{H}$, respectively. Adapted from reference [144]

investigated the adsorption of several common gas molecules $\left(\mathrm{CO}, \mathrm{SO}_{2}, \mathrm{NH}_{3}, \mathrm{CO}_{2}, \mathrm{~N}_{2}, \mathrm{H}_{2} \mathrm{O}\right.$, and $\left.\mathrm{H}_{2}\right)$ on Li-decorated $\mathrm{T}$ graphene, using DFT [162]. They found that Lidecorated $\mathrm{T}$ graphene exhibited a higher sensitivity to $\mathrm{CO}$. Their work provided an insight to build promising gas detectors based on graphene. Wu et al. reported that graphene nanosheets/PANI nanocomposite with a different mass ratio was synthesized and investigated [163]. This hybrid was able to fabricate methane sensor, the detection limit of which decreased with the increasing mass ratio of graphene to PANI. Herein, we summarized recent researches about graphene-based gas sensors for $\mathrm{CO}_{2}, \mathrm{CO}$ and $\mathrm{CH}_{4}$ detection, as shown in Table 5 .

\subsection{Sulfur Dioxide and Hydrogen Sulfide Detection}

As main atmospheric pollutants, sulfur dioxide $\left(\mathrm{SO}_{2}\right)$ and hydrogen sulfide $\left(\mathrm{H}_{2} \mathrm{~S}\right)$ are very harmful to mankind and animals. In recent years, some researchers reported some novel gas sensors for the detection of $\mathrm{SO}_{2}$ and $\mathrm{H}_{2} \mathrm{~S}$ based on graphene composites. Shen and his team demonstrated that GO nanosheets derived from chemically tailoring acted as a promising material for $\mathrm{SO}_{2}$ gas sensing [166]. The edgetailored GO nanosheet-based chemiresistive sensor had a wide range of sensitivity as well as a quick response and short recovery time at room temperature. First principle calculations based on DFT were often used to predict the physical properties of specific materials. Through DFT calculation, Liu et al. drew a conclusion that Al-doped defective graphene owned a high reactivity toward $\mathrm{SO}_{2}$, indicating its potential application in $\mathrm{SO}_{2}$ detection [167]. Similarly, Shao et al. found that $\mathrm{Cr}$-doped zigzag graphene nanoribbons were also considered as the potential candidates for $\mathrm{SO}_{2}$ molecular sensors [168]. Tensile strain effects on enhanced adsorption of $\mathrm{H}_{2} \mathrm{~S}$ molecules on Ag-decorated defective graphene composite were investigated using first principles calculations based on DFT by Xian's team [169]. Their calculations illustrated that a relatively modest tensile 
Table 4 A summary of recent researches about graphene-based gas sensors for $\mathrm{H}_{2}$ detection at room temperature

\begin{tabular}{|c|c|c|c|c|c|c|}
\hline Sensing material & Structure of sensor & Target gas & $T_{\text {res }}(\mathrm{s})$ & LOD & $T_{\text {rec }}(\mathrm{s})$ & Ref. \\
\hline $\mathrm{Pt} / \mathrm{RGO} / \mathrm{SiC}$ & FET & $\mathrm{H}_{2}$ & 300 & $\begin{array}{l}\text { Voltage shift of } \approx 100 \mathrm{mV} \\
\quad \text { for } 1 \% \mathrm{H}_{2}\left(100{ }^{\circ} \mathrm{C}\right)\end{array}$ & - & [145] \\
\hline $\mathrm{GR} / \mathrm{Pt}$ & Chemiresistor & $\mathrm{H}_{2}$ & 540 & $16 \% / 4$ vol\% & - & [140] \\
\hline Multilayered GR/Pd nanoribbon & Chemiresistor & $\mathrm{H}_{2}$ & 21 & $55 \% / 40 \mathrm{ppm}$ & 23 & [146] \\
\hline $\mathrm{GR} / \mathrm{Pt}$ & Chemiresistor & $\mathrm{H}_{2}$ & 700 & $1 \%$ concentration $\left(175^{\circ} \mathrm{C}\right)$ & 700 & [141] \\
\hline $\mathrm{GR} / \mathrm{Pt}$ & Chemiresistor & $\mathrm{H}_{2}$ & 120 & $80 \% / 1 \%$ concentration & 1200 & [142] \\
\hline $\mathrm{GR} /(\mathrm{Pt}+\mathrm{Pd})$ & Chemiresistor & $\mathrm{H}_{2}$ & $<2$ & $2 \%$ concentration $\left(40^{\circ} \mathrm{C}\right)$ & 18 & [143] \\
\hline GR/Pd & Chemiresistor & $\mathrm{H}_{2}$ & - & $1 \%$ concentration & - & [147] \\
\hline GR/Pd & Chemiresistor & $\mathrm{H}_{2}$ & 900 & $20 \mathrm{ppm}$ & 1800 & [148] \\
\hline GR & First-principle calculation & $\mathrm{H}_{2}$ & - & - & - & [149] \\
\hline $\mathrm{RGO} / \mathrm{TiO}_{2} /(\mathrm{Pd}+\mathrm{Pt})$ & Chemiresistor & $\mathrm{H}_{2}$ & 18 & $92 \% / 500 \mathrm{ppm}\left(180^{\circ} \mathrm{C}\right)$ & 29 & [150] \\
\hline $\mathrm{RGO} / \mathrm{SnO}_{2}+\mathrm{Pt}$ & Chemiresistor & $\mathrm{H}_{2}$ & 5 & $1 \%$ concentration & 4 & [151] \\
\hline $\mathrm{RGO} / \mathrm{Pd}$ & Chemiresistor & $\mathrm{H}_{2}$ & - & $0.20 \%$ & - & [152] \\
\hline GR with mono-atom-vacancy & First-principle calculation & $\mathrm{H}_{2}$ & - & $10^{-35} \mathrm{~mol} \mathrm{~L}^{-1}$ & - & [144] \\
\hline RGO/Pd & Chemiresistor & $\mathrm{H}_{2}$ & 1200 & $0.4 \% / 0.2 \mathrm{ppm}$ & 900 & [153] \\
\hline GO & Chemiresistor & $\mathrm{H}_{2}$ & 270 & $6 \% / 800 \mathrm{ppm}$ & 306 & [154] \\
\hline PMMA/Pd NPs + SL GR & Chemiresistor & $\mathrm{H}_{2}$ & 108 & $66 \% / 2 \%$ & 330 & [155] \\
\hline $\mathrm{GR} / \mathrm{SnO}_{2} \mathrm{NPs}$ & FET & $\mathrm{H}_{2}$ & 1.2 & $3 / 100 \mathrm{ppm}$ & 1.6 & [156] \\
\hline GO/PEDOT:PSS & Chemiresistor & $\mathrm{H}_{2}$ & 30 & $4.2 \% / 100 \mathrm{ppm}$ & 25 & [157] \\
\hline
\end{tabular}

$R G O$ reduced graphene oxide, GR Graphene, PMMA Polymethylmethacrylate, NPs Nanoparticles, $S L$ Single layer

Table 5 A summary of recent researches about graphene-based gas sensors for $\mathrm{CO}_{2}, \mathrm{CO}$, and $\mathrm{CH}_{4}$ detection at room temperature

\begin{tabular}{|c|c|c|c|c|c|c|}
\hline Sensing material & Structure of sensor & Target gas & $T_{\text {res }}(\mathrm{s})$ & LOD & $T_{\text {rec }}(\mathrm{s})$ & Ref. \\
\hline GR/PANI & Chemiresistor & $\mathrm{CH}_{4}$ & 85 & $10 \mathrm{ppm}$ & 45 & [163] \\
\hline GR/Li & First-principle calculation & $\mathrm{CO}$ & - & - & - & [162] \\
\hline GR prepared by mechanical cleavage & Chemiresistor & $\mathrm{CO}_{2}$ & 8 & $9 \% / 10 \mathrm{ppm}$ & - & [164] \\
\hline $\mathrm{GR} / \mathrm{Y}_{2} \mathrm{O}_{3}$ QDs & Chemiresistor & $\mathrm{CO}_{2}$ & - & $1.08 \% / 35 \mathrm{ppm}$ & - & [159] \\
\hline Few-layered GR & Chemiresistor & $\mathrm{CO}_{2}$ & 11 & $3 \mathrm{ppm}$ & 14 & [158] \\
\hline GR reduced by hydrogen plasma & Chemiresistor & $\mathrm{CO}_{2}$ & 240 & $2 \% / 300 \mathrm{ppm}$ & 240 & [165] \\
\hline $\mathrm{GR} / \mathrm{Sb}_{2} \mathrm{O}_{3} \mathrm{QDs}$ & Chemiresistor & $\mathrm{CO}_{2}$ & 16 & $50 \mathrm{ppm}$ & 22 & [160] \\
\hline $\mathrm{GR} / \mathrm{Al}_{2} \mathrm{O}_{3} \mathrm{QDs}$ & Chemiresistor & $\mathrm{CO}_{2}$ & 14 & $100 \mathrm{ppm}\left(125^{\circ} \mathrm{C}\right)$ & 22 & [161] \\
\hline
\end{tabular}

GR Graphene, QDs quantum dots

strain around $8 \%$ in defective graphene can greatly increase the binding energy of $\mathrm{Ag}$ adatom by $44 \%$, indicating enhanced stabilization of $\mathrm{Ag}$ adatom on defective graphene, while the tensile strain had little effects on the sensitivity of Ag-decorated defective graphene composite to $\mathrm{H}_{2} \mathrm{~S}$ molecule. Zhou et al. fabricated a $\mathrm{RGO} / \mathrm{Cu}_{2} \mathrm{O}$ nanocomposite-based sensor with a very low detection limit of $5 \mathrm{ppb}$ at room temperature, which might be on account of high surface activity adsorption of $\mathrm{H}_{2} \mathrm{~S}$ gas molecules due to the absence of any surfactant capping [170]. So far, it is the lowest LOD in the similar types of sensors. Jiang and co- workers had also carried out a fantastic work to realize ultrafast response to $\mathrm{H}_{2} \mathrm{~S}$ within $500 \mu \mathrm{s}$, as well as a fast recovery time of less than $30 \mathrm{~s}$ [171]. They used magnetic fields with different orientations to control fabrication progress of the $\mathrm{Fe}_{2} \mathrm{O}_{3}$ /graphene nanosheets. The experimental results illustrated that structural orientation of nanosheets played an essential role in maximizing efficiency of the device. In a word, their remarkable jobs and significant results have greatly promoted the development of graphene-based gas sensors. Table 6 summarized recent researches about $\mathrm{SO}_{2}$ and $\mathrm{H}_{2} \mathrm{~S}$ detection based on graphene. 
Table 6 A summary of recent researches about graphene-based gas sensors for $\mathrm{SO}_{2}$ and $\mathrm{H}_{2} \mathrm{~S}$ detection at room temperature

\begin{tabular}{|c|c|c|c|c|c|c|}
\hline Sensing material & Structure of sensor & Target gas & $T_{\text {res }}(\mathrm{s})$ & LOD & $T_{\text {rec }}(\mathrm{s})$ & Ref. \\
\hline GR & FET & $\mathrm{SO}_{2}$ & 120 & $100 \% / 50 \mathrm{ppm}$ & 120 & [172] \\
\hline Edge-tailored GO & FET & $\mathrm{SO}_{2}$ & - & $5 \mathrm{ppm}$ & - & [166] \\
\hline Al-dropped defective GR & First-principle calculation & $\mathrm{SO}_{2}$ & - & - & - & [167] \\
\hline Cr-doped zigzag GR nanoribbons & First-principle calculation & $\mathrm{SO}_{2}$ & - & - & - & [168] \\
\hline Ag-decorated defective GR & First-principle calculation & $\mathrm{H}_{2} \mathrm{~S}$ & - & - & - & [169] \\
\hline Ag-supported Si-doped GR & First-principle calculation & $\mathrm{H}_{2} \mathrm{~S}$ & - & - & - & [173] \\
\hline Fe-dropped defective GR & First-principle calculation & $\mathrm{H}_{2} \mathrm{~S}$ & - & - & - & [174] \\
\hline $\mathrm{RGO}+\mathrm{Cu}_{2} \mathrm{O}$ nanocrystal & Chemiresistor & $\mathrm{H}_{2} \mathrm{~S}$ & 120 & $11 \% / 5 \mathrm{ppb}$ & 120 & {$[170]$} \\
\hline PSS-doped RGO/PANI & Chemiresistor & $\mathrm{H}_{2} \mathrm{~S}$ & $<90$ & $1 \mathrm{ppm}$ & 150 & [175] \\
\hline $\mathrm{RGO} / \mathrm{SnO}_{2} \mathrm{NFs}$ & Chemiresistor & $\mathrm{H}_{2} \mathrm{~S}$ & $<198$ & $1 \mathrm{ppm}\left(200^{\circ} \mathrm{C}\right)$ & $<114$ & [176] \\
\hline $\mathrm{RGO} / \mathrm{Fe}_{2} \mathrm{O}_{3}$ & Chemiresistor & $\mathrm{H}_{2} \mathrm{~S}$ & $500 \mu \mathrm{s}$ & $15 \mathrm{ppm}\left(190^{\circ} \mathrm{C}\right)$ & $<30$ & [171] \\
\hline GR/porous $\mathrm{WO}_{3} \mathrm{NFs}$ & Chemiresistor & $\mathrm{H}_{2} \mathrm{~S}$ & - & $3.9 \% / 100 \mathrm{ppb}\left(300^{\circ} \mathrm{C}\right)$ & 600 & [177] \\
\hline Zigzag $\mathrm{Gr} / \mathrm{Cu}$ & First-principle calculation & $\mathrm{H}_{2} \mathrm{~S}$ & & & & [178] \\
\hline $\mathrm{GR} / \mathrm{Ti}$ or $\mathrm{GR} / \mathrm{Sn}$ & First-principle calculation & $\mathrm{SO}_{2} / \mathrm{H}_{2} \mathrm{~S}$ & & & & [179] \\
\hline
\end{tabular}

$R G O$ reduced graphene oxide, $G O$ Graphene oxide, GR Graphene, PSS poly 4-styrenesulfonic acid, NFs Nanofibers

\subsection{Volatile Organic Compounds, Explosives, and Chemical Warfare Agents Detection}

Volatile organic compounds (VOCs) are organic chemicals that have a high vapor pressure at room temperature. VOCs are numerous, varied, and ubiquitous. They refer to gases which containing organic compounds, including aromatic hydrocarbon, nitro hydrocarbon, halogenated hydrocarbon, long chain alkane, alcohol, ether, acetone, grease, hydrazine, and so on. Most of them are toxic, flammable, and explosive gases. At present, as the terrible activities are of high frequency, the detection of explosives and chemical warfare agents (CWAs) attracts an increasing attention in many fields and is becoming a hot topic for research.

In general, the study of graphene-based vapor sensors for detection of VOCs, explosives, and CWAs is relatively immature. As such, many novel approaches have been developed to explore the terra incognita.

Dua and co-works developed a rapid and one-step method for the conversion of exfoliated GO into RGO using aqueous vitamin $\mathrm{C}$ as a mild and green reducing agent [180]. The RGO-based gas sensor fabricated by inkjet printing techniques was able to detect VOCs at ppb level at room temperature. In 2011, Jiang et al. developed a facile and novel route to synthesize $\mathrm{Al}_{2} \mathrm{O}_{3}$ /graphene nanocomposites with the aid of supercritical $\mathrm{CO}_{2}$ derived from graphene oxide [181]. The ethanol-sensing features of as-synthesized $\mathrm{Al}_{2} \mathrm{O}_{3}$ /graphene nanocomposites were firstly reported on the basis of catalytic chemiluminescence mechanisms. They boldly broke through the limitation of the traditional preparation and measurement methods, leading a new way to tackle relevant problems. In the same year, Zhang et al. reported an intrinsic polymer optical fiber (POF) sensor based on graphene, which was described for the purpose of acetone vapor sensing for the first time [182]. Gautam's team had systematically studied the key parameters (response, recovery, repeatability and reliability) of the sensor based on gold and platinum nanoparticles functionalized graphene for the detection of different organic vapors (acetic acid, ethanol, and acetone) at ppm levels [183].

Tang et al. established a prominent analytical platform for electrochemical sensing determination of nitroaromatic explosive compounds, such as 2,4,6-trinitrotoluene (TNT), which was superior to other TNT-sensing platforms, using uniform and rich-wrinkled graphene films prepared by electrophoretic deposition techniques [184]. The detection of TNT with the concentration of $0.2 \mathrm{ppb}$ in a phosphate buffered saline by differential pulse voltammetry was realized. Fan's team utilized water-soluble and surfaceunmodified graphene quantum dots, which were prepared by a chemical approach from GO, as a novel, effective, and simple fluorescent-sensing platform for ultrasensitive detection of TNT in solution by fluorescence resonance energy transfer quenching for the first time [185]. The detection limit was about $0.495 \mathrm{ppm}$. Liu et al. used surface enhanced Raman scattering to realize ultratrace detection of TNT $\left(5 \times 10^{-16} \mathrm{M}\right)$, which was based on 
p-aminothiophenol functionalized graphene nanosheets decorated with silver nanoparticles [186]. GO modified Au electrode was used as a carbon electrode catalyst for the electrochemical oxidation of chemical warfare agent simulant thiodiglycol (TDG) at room temperature by Singh and his team [187]. Their experiments indicated that GO would be a better alternative material for transition metals in the degradation of chemical warfare agents as well as environmental pollutants. Ganji et al. drew a conclusion that aluminum nitride graphene had stronger interaction with the DMMP molecule and could provide more sensitive signal for a single DMMP molecule, compared with pristine graphene, boron nitride graphene, using ab initio van der Waals density functional calculations [188]. Though some detection process of their experiments could only take place in solution, their excellent work is a useful reference for graphene-based gas detection and has contributed a lot to practical applications in national defense and daily life. Herein, we summarized recent researches about graphene-based vapor sensors for VOCs, explosives, and CWAs detection, as shown in Table 7.

\section{Response Mechanisms}

We have given a brief introduction to the classification of gas/vapor sensors. Considering that the gas-sensing mechanisms of graphene is uncertain and related research is rare, herein, we just give a recognized point of view as a general introduction of the reference of other related literatures [200-203].

Graphene is intrinsically inert and nonselective. Its great efficiency to conduct electricity and distinguishing features of ballistic transport of charges decide that this two-dimensional material is an ideal candidate to serve as a platform or a supporter, in which we can realize many specific functions by doping or compositing with other materials. Once combined with other materials physically or chemically, graphene can show the characteristics of the semiconductor in normal circumstances, of which conductivity is determined by carriers' concentration. For chemiresistor-type sensors, sensing materials show response to externalities by the change of conductivity, that is the variation of concentration of hole or electron carriers.

Table 7 A summary of recent researches about graphene-based vapor sensors for VOCs, explosives, and CWAs detection at room temperature

\begin{tabular}{|c|c|c|c|c|c|c|}
\hline Sensing material & Structure of sensor & Target gas & $T_{\text {res }}(\mathrm{s})$ & LOD & $T_{\text {rec }}(\mathrm{s})$ & Ref. \\
\hline RGO/PPD & Chemiresistor & DMMP & 1080 & $5 \% / 5 \mathrm{ppm}$ & 360 & {$[63]$} \\
\hline Few-layered GR & Chemiresistor & LPG & 5 & $4 \mathrm{ppm}$ & 18 & [158] \\
\hline $\mathrm{RGO} / \mathrm{SnO}_{2} \mathrm{NFs}$ & Chemiresistor & Acetone & $<198$ & $100 \mathrm{ppb}\left(350{ }^{\circ} \mathrm{C}\right)$ & $<114$ & [176] \\
\hline $\mathrm{GO} / \mathrm{Au}$ electrode & & TDG & & & & [187] \\
\hline Al nitride GR & First-principle calculation & DMMP & & & & [188] \\
\hline Uniform and rich-wrinkled GR & & TNT & & $0.2 \mathrm{ppb}$ & & [184] \\
\hline GQDs & FRET quenching & TNT & & $0.495 \mathrm{ppm}$ & & [185] \\
\hline GR/Ag + PATP & SERS & TNT & & $5 \times 10^{-16} \mathrm{M}$ & & [186] \\
\hline Printed RGO & Chemiresistor & VOCs & & ppb level & & [180] \\
\hline $\mathrm{RGO} / \mathrm{Al}_{2} \mathrm{O}_{3}$ & $\mathrm{CL}$ & Ethanol & 10 & $1.5 \mathrm{mg} / \mathrm{mL}^{-1}\left(200{ }^{\circ} \mathrm{C}\right)$ & $<100$ & [181] \\
\hline GR on POF & OFS & Acetone & & $44 \mathrm{ppm}$ & & [182] \\
\hline RGO & FET array & Ethanol & 300 & $17 \%$ & & [189] \\
\hline $\mathrm{GR} /(\mathrm{Au}+\mathrm{Pt})$ & Chemiresistor & VOCs & & $30 \% / 100 \mathrm{ppm}$ & & [183] \\
\hline $\mathrm{GO} / \mathrm{PPr}$ & Chemiresistor & Toluene & & $24 \mathrm{ppm}$ & & [190] \\
\hline Ni NPs/Nafion/GR & CV \& EIS & Ethanol & & $0.12 \mathrm{mM}$ & & [191] \\
\hline $\mathrm{RGO} / \mathrm{ZnFe}_{2} \mathrm{O}_{4}$ & Chemiresistor & Acetone & 4 & $10 \mathrm{ppm}\left(275^{\circ} \mathrm{C}\right)$ & 18 & [192] \\
\hline Si dropped $\mathrm{BC}_{3} \mathrm{GR}$ & First-principle calculation & Acetone & & & & [193] \\
\hline Self-Assembled GR/PDA & Colorimetric sensor & VOCs & & $0.01 \%$ & & [194] \\
\hline $\mathrm{Co}_{3} \mathrm{O}_{4} \mathrm{NFs}+\mathrm{Ir} \mathrm{NPs}+\mathrm{GO}$ & Chemiresistor & Acetone & & $1.18 \% / 120 \mathrm{ppb}\left(300{ }^{\circ} \mathrm{C}\right)$ & & [195] \\
\hline RGO coated optical fiber & OFS & Methanol \& Ethanol & & $100 \mathrm{ppm}$ & & [196] \\
\hline RGO/Ag & OFS & Ethanol & 11 & $1 \%$ & 6 & [197] \\
\hline $\mathrm{RGO} / \mathrm{ZnO}+\mathrm{Ag} \mathrm{NPs}$ & Chemiresistor & Acetylene & 21.2 & $21.2 / 100 \mathrm{ppm}\left(150^{\circ} \mathrm{C}\right)$ & 80 & [198] \\
\hline $\mathrm{RGO} / \mathrm{ZnO}+\mathrm{Ag} \mathrm{NPs}$ & Chemiresistor & Acetylene & 57 & $12.3 / 100 \mathrm{ppm}\left(200^{\circ} \mathrm{C}\right)$ & 90 & [199] \\
\hline
\end{tabular}

$R G O$ reduced graphene oxide, $G O$ graphene oxide, $G R$ graphene, $T D G$ thiodiglycol, $G Q D s$ graphene quantum dots, FRET fluorescence resonance energy transfer quenching, PATP p-aminothiophenol, SERS surface enhanced Raman scattering, $C L$ catalytic chemiluminescence, $P O F$ polymer optical fiber, $P P r$ polypyrene, $N P$ s nanoparticles, $C V$ cyclic voltammetry, $C I S$ electrochemical impedance spectroscopy, $P D A$ polydiacetylene, NFs Nanofibers, OFS optical fiber sensor 
Bulk porous materials usually have a large specific surface area, hence gas molecules can be easily adsorbed, following by the interaction between gas molecules and specific groups in the graphene surface, and then the gas molecules capture or donate electrons from the sensing material, which changes concentration of the semiconductor's carriers.

Different doping and reaction conditions may lead to different types of graphene-based semiconductors (p-type or n-type). As we all know, p-type semiconductors refer to those who have a larger hole concentration than electron concentration. In p-type semiconductors, holes are the majority carriers and electrons are the minority carriers. As opposed to p-type semiconductors, n-type semiconductors have a larger electron concentration than hole concentration. In n-type semiconductors, electrons are the majority carriers and holes are the minority carriers. For example, one doped graphene shows characteristic of n-type semiconductors: when it is exposed to a reducing atmosphere, such as $\mathrm{NH}_{3}$, it would get electrons from the gas molecules, leading to an increase of the electron concentration, i.e., a decrease of graphene's resistance occurs. Likewise, when it is exposed to an oxidation atmosphere, such as $\mathrm{NO}_{2}$, it will deliver electrons to the gas molecules, leading an increase of hole concentration, leading to an increase of graphene's resistance. Figure 13 demonstrates a general progress of gas sensing, which has been described above. This is the old and universal theory called "Oxygen anion barrier model," which used to illustrate the mechanism of gassensing progress based on metal-oxide semiconductors [204-207].

Zhou et al. have found that the total flow rate had a significant effect on the initial electric resistance of the sensors and their sensing properties to target gases. In addition, an appropriate quantity of deposited RGO solution was critical for sensors' sensing response and sensitivity. Finally, they raise a novel sensing mechanism for chemiresistors based on RGO at room temperature [208]. Zhu and his team had done an important job to prove that the oxygen functional groups presiding on the surface of reduced graphene oxide could play a vital role in the response for one specific gas. Two types of unprecedented effects could be attributed to the presence of oxygen functional groups, i.e., the selective binding interactions (strong or weak) to different gas molecules, and the impendence to charge interaction between gas molecules and sp2-hybridized carbon areas in RGO [209]. Sometimes, p-type graphene and n-type graphene can transform from one to another by changing the annealing temperature. Wang et al. explored this interesting phenomenon that the slightly reduced p-type graphene showed ultrasensitive gas sensing at room temperature, with a response of $58 \%$ to $1 \mathrm{ppm}$ ethanol, while the graphene could become n-type and insensitive to gas sensing, with a low response of $0.5 \%$ to $50 \mathrm{ppm}$ ethanol, by simply increasing the annealing temperature to about $300{ }^{\circ} \mathrm{C}$ [210].

\section{Conclusions}

\subsection{Existing Problems}

The interests in the study of nanomaterials have escalated in the recent decades, while the application is still in its infancy. This so-called "game changing" technology has met, one after another, many impediments on its way to large-scale industrialization [40]. Can graphene and graphene-based devices get through the close siege?

Theory can indicate a direction for practice. However, till now, the mechanism of gas sensing based on nanomaterials is not very clear, and quantitative calculation is almost impossible. There is little doubt that graphene thin film has great sensitivity; however, this may lead to another result that it is sensitive to many kinds of gases. Crosssensitivity means sensor shows similar responses to the different types of gases, and this character may result in false detecting. For example, cross-sensitivity can be a problem in the detection of ethylene oxide, as ethylene oxide requires a very active working electrode catalyst and high operating potential for its oxidation. Therefore, gases which are more easily oxidized like alcohols and carbon monoxide will also give a response. Once a technique reaches the stage of mass production, it will be a completely different compared with the laboratory. One of dire challenges we confronted with is the nonrepeatability of device fabrication. From preparation of sensing materials to construction of gas/vapor sensors, from building of experimental platforms to characterization parameters, none of the uniform criteria is listed, and neither specification of laboratory equipment nor the unified presentation of technological process and synthesis method was reported.

\subsection{Solutions and Prospects}

In order to overcome the problems mentioned above, we put forward several worthwhile schemes and directions. Sensing materials are the core of gas detection in a realworld application. The development of synthesizing novel materials with high sensitivity and selectivity is one of the mainstream trends of gas sensors. Multicomponent classification and hybrid nanostructures which have multifunctions and outstanding performances in practical tasks are at the forefront of current research. By the improved preparation techniques such as modification of graphene, 3D structure tailoring, and thermal treatments, we may make sensors to suit the ideal state. 


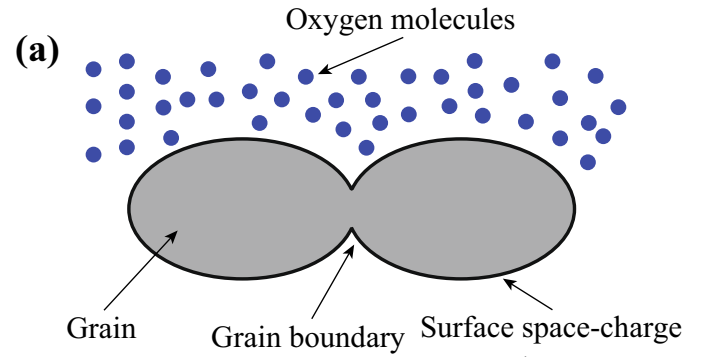

layer

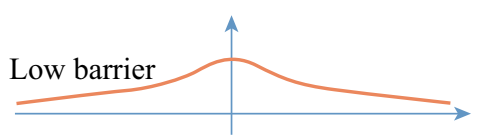

Grain boundary
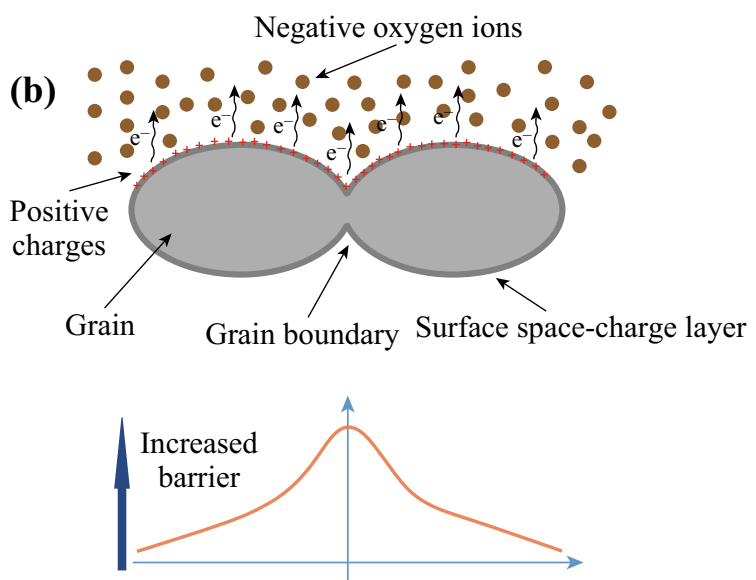

Grain boundary

(c)

Reducing gases

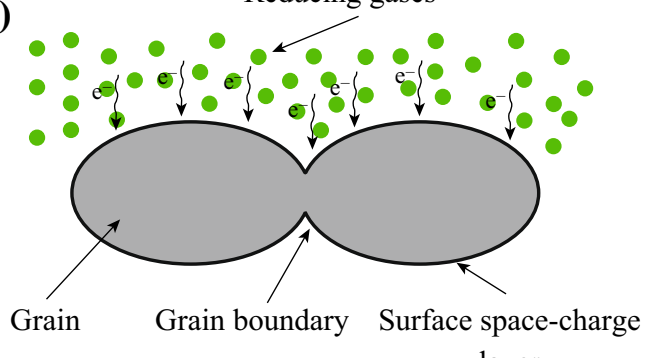

layer

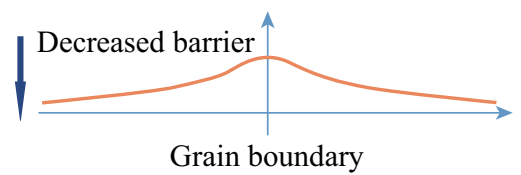

Fig. 13 A general progress of gas sensing based on chemiresistor

Figure 14 shows a stark contrast between the responses of the graphene/palladium nanoparticle composites to $\mathrm{H}_{2}$, $\mathrm{NO}_{2}$, and humidity and those of pristine graphene. The comparison explicitly instructs that modification can change the sensing properties to a large extent. Yavari and his team manufactured a macro-graphene foam-like 3D network which had both the advantages of the nanostructured and conventional solid-state and conducting-polymer sensors. A surprising sensing property and ppb level detection of $\mathrm{NH}_{3}$ and $\mathrm{NO}_{2}$ in air at room temperature had been demonstrated for this robust, flexible, and novel material [211]. The microporous structure of this graphene foam is demonstrated in Fig. 15.

Based on the technology of microelectromechanical systems, multiple sensor arrays, in which every unit has different heterostructure and shows different sensing characteristics, can be assembled and expected to have higher sensitivity and improved selectivity. Yi et al. presented a novel materials-sensor integration fabrication strategy, which involved the introduction of micro-injection to fabricate sensing devices. The $\mathrm{In}_{2} \mathrm{O}_{3}$ nanowire-like

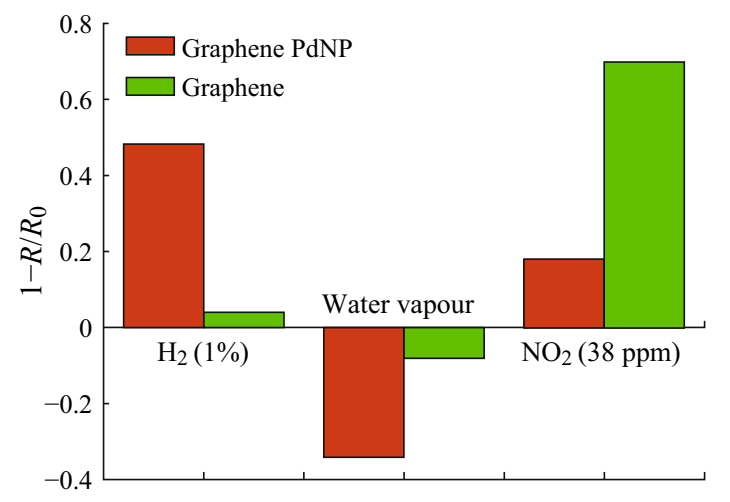

Fig. 14 Comparison of the responses to hydrogen, $\mathrm{NO}_{2}$, and humidity of the graphene/Pd NPs composite and of graphene. Adapted from reference [147]

network directly on the surface of coplanar sensors array by structure replication from sacrificial CNTs was obtained on the basis of screen-printing technology and calcination. The device showed that excellent gas-sensing properties benefited from fabrication of coplanar gas sensors arrays 

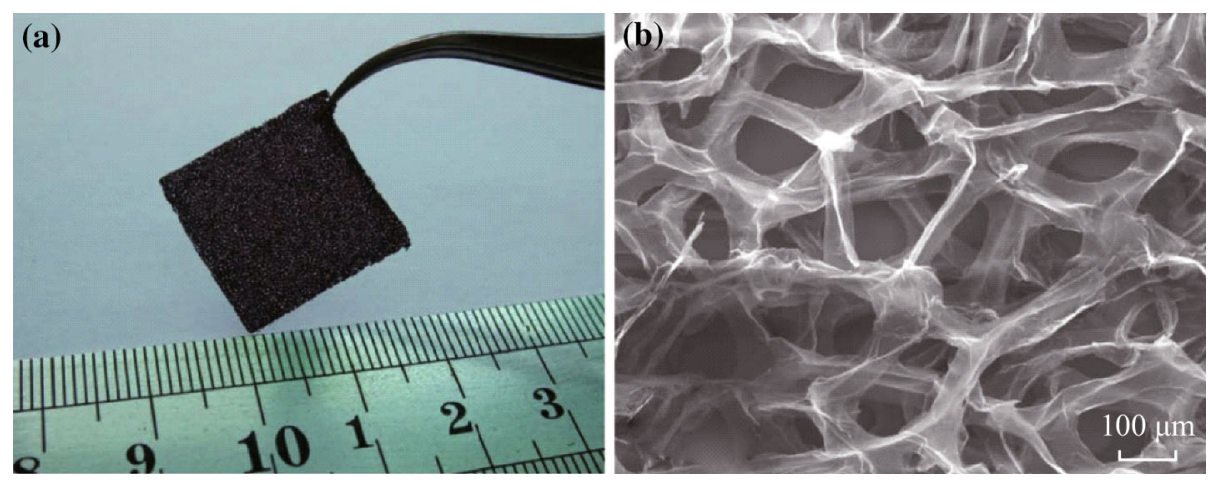

Fig. 15 a Photograph and $\mathbf{b}$ scanning electron micrograph of the microporous graphene foam structure showing a continuous network of 3D interconnected graphene sheets that comprise the walls of the foam-like structure. The robust and flexible graphene foam strips can be easily handled and manipulated. Adapted from reference [211]

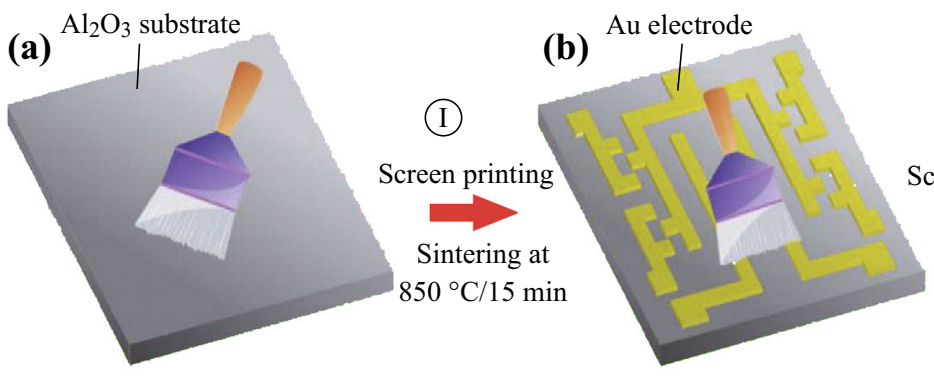

Pretreatment of coplanar sensor
(II)

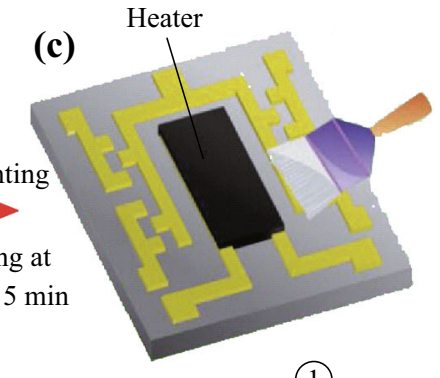

(1)

Sintering printing dried at $350^{\circ} \mathrm{C} / 2 \mathrm{~h}$

Screen printing combined with micro-injecting and calcination (SPMIC)

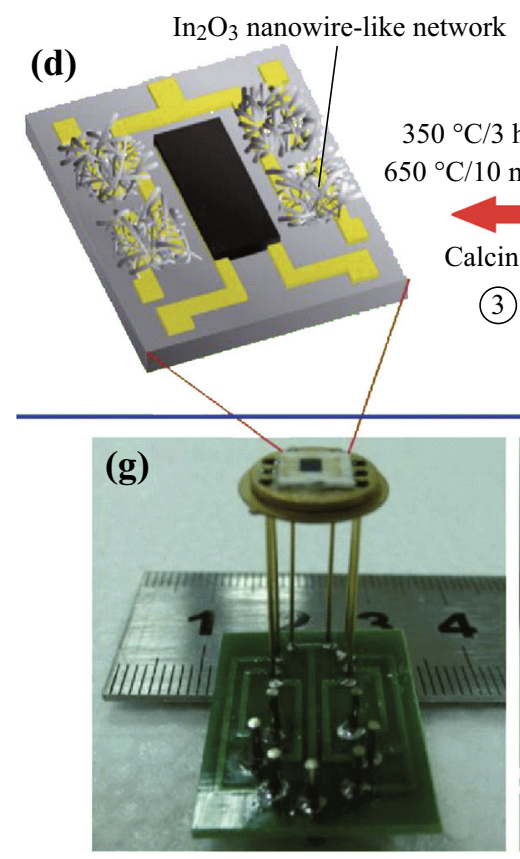

(e)

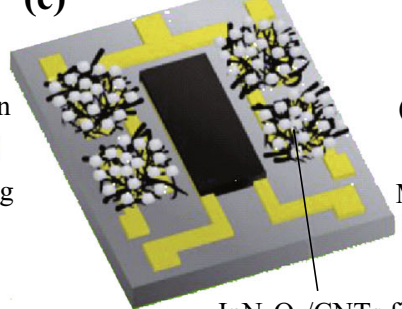

$\mathrm{InN}_{3} \mathrm{O}_{9} / \mathrm{CNTs}$ film (f)

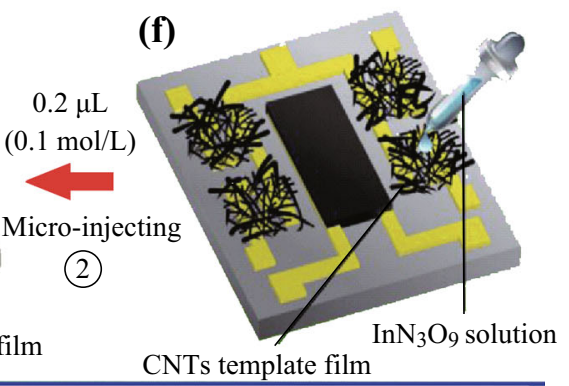

CNTs template film
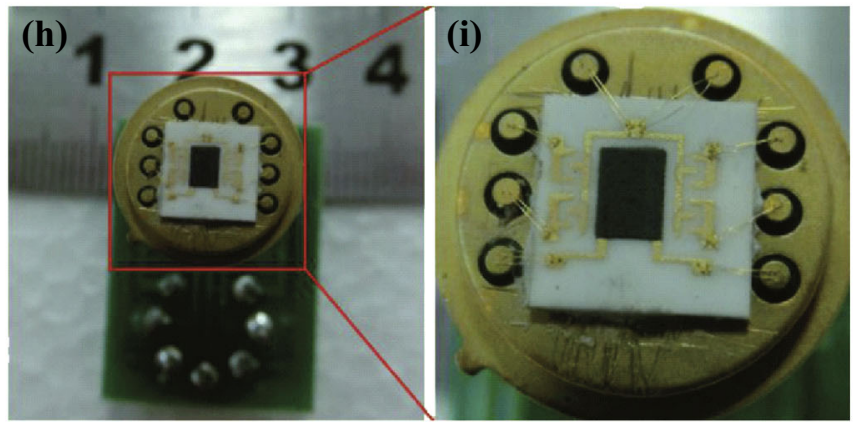

The device

Fig. 16 Schematic diagram of the preparation of sensing material and the construction of the device. Adapted from reference [212] 


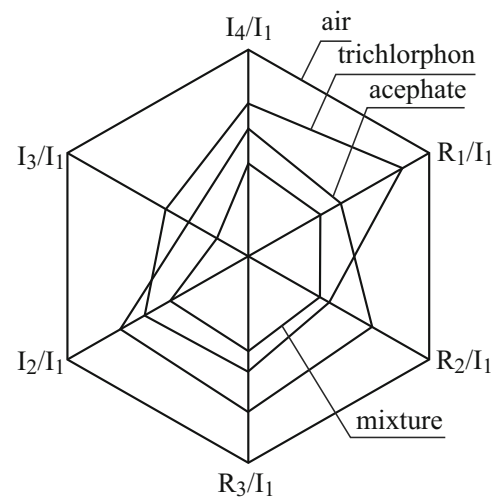

(a)

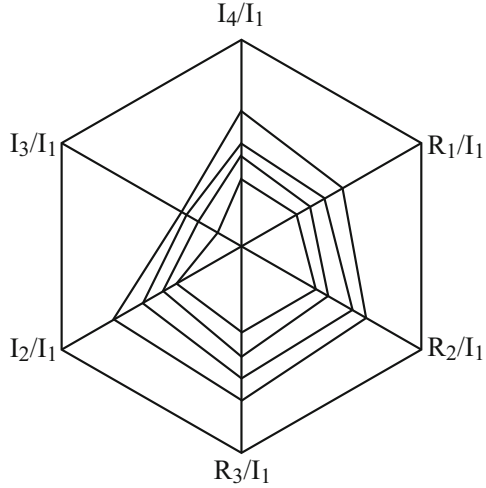

(b)

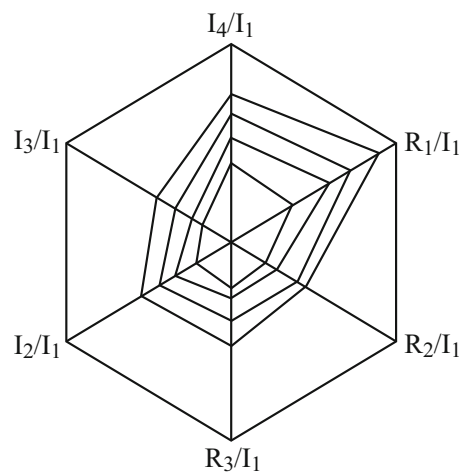

(c)

Fig. 17 a Characteristic responses of the relative intensities of the higher harmonics. $R_{i}$ and $L_{i}$ are the real and imaginary components of the $i$ th higher harmonic. The analyzed data correspond to the resistance values in the concentrations of $1.053 \mu \mathrm{g} \mathrm{L}^{-1}$ trichlorphon, $0.75 \mu \mathrm{g} \mathrm{L} \mathrm{L}^{-1}$ acephate, and their mixture. $\mathbf{b}, \mathbf{c}$ Effects of concentrations of pesticide vapor on the relative intensities of the higher harmonic. The concentrations from inside to outside are $0.75,2.25,3.75$, and $5.25 \mu \mathrm{g} \mathrm{L}^{-1}$; and $1.053,3.159,5.265$, and $7.371 \mu \mathrm{g} \mathrm{L}{ }^{-1}$, respectively. b acephate, $\mathbf{c}$ trichlorphon. Adapted from reference [213]

and materials, which had special porous nanowire-like network micromorphology. Figure 16 shows a schematic diagram depicting the procedure to prepare the porous $\mathrm{In}_{2} \mathrm{O}_{3}$ nanowire-like network and the related devices.

The employment of the new signal-processing technology and recognition algorithm based on single-chip system is an important direction for the development of gassensing devices. By the application of dynamic detection, signal processing, and recognition algorithm, gas/vapor sensors with low power consumption, portable volume, and intelligent operation could be achieved [213-215]. Huang and his team had successfully achieved qualitative and quantitative analysis of organophosphorus pesticide residues using temperature-modulated $\mathrm{SnO}_{2}$-based gas sensor, and the quantitative analyses of the pure pesticide vapor and their mixture were performed by fast Fourier transformation [213]. The results showed that the amplitudes of the higher harmonics exhibited characteristic changes depending on the vapor concentration ratio and the kinetics on the sensor surface, as shown in Fig. 17. They made a significant exploratory development in the rapid detection of pesticide residue vapors.

The future of graphene-based gas/vapor sensors looks bright. Continued progress in this field will overcome the current challenges, get through the close siege, and lead to a class of gas sensors with superior sensitivity, excellent selectivity, reduced size, and extended lifetimes for a wide range of environments and applications.

Acknowledgments The authors gratefully acknowledge the financial supports provided by the National Basic Research Program of China (2013CB932500), the National Natural Science Foundation of China (21171117 and 61574091), the Program for New Century Excellent Talents in University (NCET-12-0356), the Program of Shanghai
Academic/Technology Research Leader (15XD1525200), Shanghai Jiao Tong University Agri-X Funding (Agri-X2015007), and the Program for Professor of Special Appointment (Eastern Scholar) at Shanghai Institutions of Higher Learning. The authors also acknowledge the analysis support received from the Instrumental Analysis Center of Shanghai Jiao Tong University and the Center for Advanced Electronic Materials and Devices of Shanghai Jiao Tong University.

Open Access This article is distributed under the terms of the Creative Commons Attribution 4.0 International License (http://creative commons.org/licenses/by/4.0/), which permits unrestricted use, distribution, and reproduction in any medium, provided you give appropriate credit to the original author(s) and the source, provide a link to the Creative Commons license, and indicate if changes were made.

\section{References}

1. J.G. Stevens, L.H. Bowen, K.M. Whatley, Moessbauer spectroscopy. Anal. Chem. 62(12), 125R-139R (1990). doi:10.1021/ ac00211a003

2. J. Janata, Chemical sensors. Anal. Chem. 64(12), 196-219 (1992). doi:10.1021/ac00036a012

3. J. Janata, M. Josowicz, D.M. DeVaney, Chemical sensors. Anal. Chem. 66(12), 207R-228R (1994). doi:10.1021/ac00084a010

4. J. Janata, M. Josowicz, P. Vanýsek, D.M. DeVaney, Chemical sensors. Anal. Chem. 70(12), 179-208 (1998). doi:10.1021/ a1980010w

5. F. Zee, J.W. Judy, Micromachined polymer-based chemical gas sensor array. Sens. Actuators B 72(2), 120-128 (2001). doi:10. 1016/S0925-4005(00)00638-9

6. Y. Itagaki, K. Deki, S. Nakashima, Y. Sadaoka, Toxic gas detection using porphyrin dispersed polymer composites. Sens. Actuators B 108(1-2), 393-397 (2005). doi:10.1016/j.snb.2004. 10.055

7. H.K. Imad, H.A. Hassan, Q.N. Abdullah, Hydrogen gas sensor based on nanocrystalline $\mathrm{SnO}_{2}$ thin film grown on bare $\mathrm{Si}$ substrates. Nano-Micro Lett. 7(2), 97-120 (2015). doi:10.1007/ s40820-015-0057-1

8. H. Bai, L. Zhao, C.H. Lu, C. Li, G.Q. Shi, Composite nanofibers of conducting polymers and hydrophobic insulating polymers: 
preparation and sensing applications. Polymer 50(14), 3292-3301 (2009). doi:10.1016/j.polymer.2009.04.066

9. M.R. Mohammadi, D.J. Fray, Development of nanocrystalline $\mathrm{TiO}_{2}-\mathrm{Er}_{2} \mathrm{O}_{3}$ and $\mathrm{TiO}_{2}-\mathrm{Ta}_{2} \mathrm{O}_{5}$ thin film gas sensors: controlling the physical and sensing properties. Sens. Actuators B 141(1), 76-84 (2009). doi:10.1016/j.snb.2009.05.026

10. J.S. Lee, O.S. Kwon, S.J. Park, E.Y. Park, S.A. You, H. Yoon, J. Jang, Fabrication of ultrafine metal-oxide-decorated carbon nanofibers for DMMP sensor application. ACS Nano 5(10), 7992-8001 (2011). doi:10.1021/nn202471f

11. C. Li, G. Shi, Three-dimensional graphene architectures. Nanoscale 4(18), 5549-5563 (2012). doi:10.1039/c2nr31467c

12. D. Wang, A. Chen, A.K. Jen, Reducing cross-sensitivity of $\mathrm{TiO}_{2}$-(B) nanowires to humidity using ultraviolet illumination for trace explosive detection. Phys. Chem. Chem. Phys. 15(14), 5017-5021 (2013). doi:10.1039/c3cp43454k

13. G. Yang, C. Lee, J. Kim, F. Ren, S.J. Pearton, Flexible graphene-based chemical sensors on paper substrates. Phys. Chem. Chem. Phys. 15(6), 1798-1801 (2013). doi:10.1039/c2cp43717a

14. Z. Chen, J. Appenzeller, J. Knoch, Y.M. Lin, P. Avouris, The role of metal-nanotube contact in the performance of carbon nanotube field-effect transistors. Nano Lett. 5(7), 1497-1502 (2005). doi:10.1021/N10508624

15. K.S. Novoselov, A.K. Geim, S.V. Morozov, D. Jiang, Y. Zhang, S.V. Dubonos, I.V. Grigorieva, A.A. Firsov, Electric field effect in atomically thin carbon films. Science 306(5696), 666-669 (2004). doi:10.1126/science.1102896

16. K.S. Novoselov, A.K. Geim, S.V. Morozov, D. Jiang, M.I. Katsnelson, I.V. Grigorieva, S.V. Dubonos, A.A. Firsov, Twodimensional gas of massless Dirac fermions in graphene. Nature 438(7065), 197-200 (2005). doi:10.1038/nature04233

17. Y. Zhang, Y.W. Tan, H.L. Stormer, P. Kim, Experimental observation of the quantum Hall effect and Berry's phase in graphene. Nature 438(7065), 201-204 (2005). doi:10.1038/ nature 04235

18. C. Berger, Z. Song, X. Li, X. Wu, N. Brown et al., Electronic confinement and coherence in patterned epitaxial graphene. Science 312(5777), 1191-1196 (2006). doi:10.1126/science. 1125925

19. A.C. Ferrari, J.C. Meyer, V. Scardaci, C. Casiraghi, M. Lazzeri et al., Raman spectrum of graphene and graphene layers. Phys. Rev. Lett. 97(18), 187401 (2006). doi:10.1103/PhysRevLett.97. 187401

20. Y.W. Son, M.L. Cohen, S.G. Louie, Energy gaps in graphene nanoribbons. Phys. Rev. Lett. 97(21), 216803 (2006). doi:10. 1103/PhysRevLett.97.216803

21. S. Stankovich, D.A. Dikin, G.H. Dommett, K.M. Kohlhaas, E.J. Zimney, E.A. Stach, R.D. Piner, S.T. Nguyen, R.S. Ruoff, Graphene-based composite materials. Nature 442(7100), 282-286 (2006). doi:10.1038/nature04969

22. A.K. Geim, K.S. Novoselov, The rise of graphene. Nat. Mater. 6(3), 183-191 (2007). doi:10.1038/nmat1849

23. M.Y. Han, B. Ozyilmaz, Y. Zhang, P. Kim, Energy band-gap engineering of graphene nanoribbons. Phys. Rev. Lett. 98(20), 206805 (2007). doi:10.1103/PhysRevLett.98.206805

24. F. Schedin, A.K. Geim, S.V. Morozov, E.W. Hill, P. Blake, M.I. Katsnelson, K.S. Novoselov, Detection of individual gas molecules adsorbed on graphene. Nat. Mater. 6(9), 652-655 (2007). doi: $10.1038 /$ nmat 1967

25. S. Stankovich, D.A. Dikin, R.D. Piner, K.A. Kohlhaas, A. Kleinhammes, Y. Jia, Y. Wu, S.T. Nguyen, R.S. Ruoff, Synthesis of graphene-based nanosheets via chemical reduction of exfoliated graphite oxide. Carbon 45(7), 1558-1565 (2007). doi:10.1016/j.carbon.2007.02.034

26. A.A. Balandin, S. Ghosh, W. Bao, I. Calizo, D. Teweldebrhan, F. Miao, C.N. Lau, Superior thermal conductivity of single-layer graphene. Nano Lett. 8(3), 902-907 (2008). doi:10.1021/ nl0731872

27. K.I. Bolotin, K.J. Sikes, Z. Jiang, M. Klima, G. Fudenberg, J. Hone, P. Kim, H.L. Stormer, Ultrahigh electron mobility in suspended graphene. Solid State Commun. 146(9-10), 351-355 (2008). doi:10.1016/j.ssc.2008.02.024

28. D. Li, M.B. Muller, S. Gilje, R.B. Kaner, G.G. Wallace, Processable aqueous dispersions of graphene nanosheets. Nat. Nanotechnol. 3(2), 101-105 (2008). doi:10.1038/nnano.2007.451

29. X. Li, X. Wang, L. Zhang, S. Lee, H. Dai, Chemically derived, ultrasmooth graphene nanoribbon semiconductors. Science 319(5867), 1229-1232 (2008). doi:10.1126/science.1150878

30. R.R. Nair, P. Blake, A.N. Grigorenko, K.S. Novoselov, T.J. Booth, T. Stauber, N.M. Peres, A.K. Geim, Fine structure constant defines visual transparency of graphene. Science 320(5881), 1308 (2008). doi:10.1126/science.1156965

31. M.D. Stoller, S. Park, Y. Zhu, J. An, R.S. Ruoff, Graphenebased ultracapacitors. Nano Lett. 8(10), 3498-3502 (2008). doi:10.1021/n1802558y

32. X. Wang, L. Zhi, K. Mullen, Transparent, conductive graphene electrodes for dye-sensitized solar cells. Nano Lett. 8(1), 323-327 (2008). doi:10.1021/n1072838r

33. A.H. Castro Neto, N.M.R. Peres, K.S. Novoselov, A.K. Geim, The electronic properties of graphene. Rev. Mod. Phys. 81(1), 109-162 (2009). doi:10.1103/RevModPhys.81.109

34. A.K. Geim, Graphene: status and prospects. Science 324(5934), 1530-1534 (2009). doi:10.1126/science.1158877

35. K.S. Kim, Y. Zhao, H. Jang, S.Y. Lee, J.M. Kim et al., Largescale pattern growth of graphene films for stretchable transparent electrodes. Nature 457(7230), 706-710 (2009). doi:10.1038/ nature 07719

36. X. Li, W. Cai, J. An, S. Kim, J. Nah et al., Large-area synthesis of high-quality and uniform graphene films on copper foils. Science 324(5932), 1312-1314 (2009). doi:10.1126/science. 1171245

37. A. Reina, X. Jia, J. Ho, D. Nezich, H. Son, V. Bulovic, M.S. Dresselhaus, J. Kong, Large area, few-layer graphene films on arbitrary substrates by chemical vapor deposition. Nano Lett. 9(1), 30-35 (2009). doi:10.1021/n1801827v

38. S. Bae, H. Kim, Y. Lee, X. Xu, J.S. Park et al., Roll-to-roll production of 30-inch graphene films for transparent electrodes. Nat. Nanotechnol. 5(8), 574-578 (2010). doi:10.1038/nnano. 2010.132

39. D.R. Dreyer, S. Park, C.W. Bielawski, R.S. Ruoff, The chemistry of graphene oxide. Chem. Soc. Rev. 39(1), 228-240 (2010). doi:10.1039/b917103g

40. R. Bogue, Nanomaterials for gas sensing: a review of recent research. Sensor Rev. 34(1), 1-8 (2014). doi:10.1108/Sr-032013-637

41. L. Al-Mashat, K. Shin, K. Kalantar-Zadeh, J.D. Plessis, S.H. Han et al., Graphene/polyaniline nanocomposite for hydrogen sensing. J. Phys. Chem. C 114(39), 16168-16173 (2010). doi:10. 1021/Jp103134u

42. X.Q. An, J.C. Yu, Y. Wang, Y.M. Hu, X.L. Yu, G.J. Zhang, $\mathrm{WO}_{3}$ nanorods/graphene nanocomposites for high-efficiency visible-light-driven photocatalysis and $\mathrm{NO}_{2}$ gas sensing. J. Mater. Chem. 22(17), 8525-8531 (2012). doi:10.1039/ C2jm16709c

43. Y. Dan, Y. Lu, N.J. Kybert, Z. Luo, A.T. Johnson, Intrinsic response of graphene vapor sensors. Nano Lett. 9(4), 1472-1475 (2009). doi:10.1021/n18033637

44. M. Malekalaie, M. Jahangiri, A.M. Rashidi, A. Haghighiasl, N. Izadi, Selective hydrogen sulfide $\left(\mathrm{H}_{2} \mathrm{~S}\right)$ sensors based on molybdenum trioxide $\left(\mathrm{MoO}_{3}\right)$ nanoparticle decorated reduced graphene oxide. Mater. Sci. Semicon. Process. 38, 93-100 (2015). doi:10.1016/j.mssp.2015.03.034 
45. J.D. Fowler, M.J. Allen, V.C. Tung, Y. Yang, R.B. Kaner, B.H. Weiller, Practical chemical sensors from chemically derived graphene. ACS Nano 3(2), 301-306 (2009). doi:10.1021/ nn800593m

46. Q. Ji, I. Honma, S.M. Paek, M. Akada, J.P. Hill, A. Vinu, K. Ariga, Layer-by-layer films of graphene and ionic liquids for highly selective gas sensing. Angew. Chem. Int. Ed. 49(50), 9737-9979 (2010). doi:10.1002/anie.201004929

47. M.M. Alaie, M. Jahangiri, A.M. Rashidi, A.H. Asl, N. Izadi, A novel selective $\mathrm{H}_{2} \mathrm{~S}$ sensor using dodecylamine and ethylenediamine functionalized graphene oxide. J. Ind. Eng. Chem. 29, 97-103 (2015). doi:10.1016/j.jiec.2015.03.021

48. S.M.J. Khadem, Y. Abdi, S. Darbari, F. Ostovari, Investigating the effect of gas absorption on the electromechanical and electrochemical behavior of graphene/ $\mathrm{ZnO}$ structure, suitable for highly selective and sensitive gas sensors. Curr. Appl. Phys. 14(11), 1498-1503 (2014). doi:10.1016/j.cap.2014.07.020

49. G. Lu, L.E. Ocola, J. Chen, Reduced graphene oxide for roomtemperature gas sensors. Nanotechnology 20(44), 445502 (2009). doi:10.1088/0957-4484/20/44/445502

50. G. Lu, S. Park, K. Yu, R.S. Ruoff, L.E. Ocola, D. Rosenmann, J. Chen, Toward practical gas sensing with highly reduced graphene oxide: a new signal processing method to circumvent run-to-run and device-to-device variations. ACS Nano 5(2), 1154-1164 (2011). doi:10.1021/nn102803q

51. S. Rumyantsev, G. Liu, M.S. Shur, R.A. Potyrailo, A.A. Balandin, Selective gas sensing with a single pristine graphene transistor. Nano Lett. 12(5), 2294-2298 (2012). doi:10.1021/ n13001293

52. H.J. Song, L.C. Zhang, C.L. He, Y. Qu, Y.F. Tian, Y. Lv, Graphene sheets decorated with $\mathrm{SnO}_{2}$ nanoparticles: in situ synthesis and highly efficient materials for cataluminescence gas sensors. J. Mater. Chem. 21(16), 5972-5977 (2011). doi:10. 1039/C0jm04331a

53. J. Yi, W. Park II, Vertically aligned $\mathrm{ZnO}$ nanorods and graphene hybrid architectures for high-sensitive flexible gas sensors. Sens. Actuators B 155(1), 264-269 (2011). doi:10.1039/C0jm04331a

54. E. Akbari, V.K. Arora, A. Enzevaee, M.T. Ahmadi, M. Khaledian, R. Yusof, Gas concentration effects on the sensing properties of bilayer graphene. Plasmonics 9(4), 987-992 (2014). doi:10.1007/s11468-014-9705-4

55. A. Omidvar, A. Mohajeri, Edge-functionalized graphene nanoflakes as selective gas sensors. Sens. Actuators B 202, 622-630 (2014). doi:10.1016/j.snb.2014.05.136

56. E. Akbari, V.K. Arora, A. Enzevaee, M.T. Ahmadi, M. Saeidmanesh, M. Khaledian, H. Karimi, R. Yusof, An analytical approach to evaluate the performance of graphene and carbon nanotubes for $\mathrm{NH}_{3}$ gas sensor applications. Beilstein J. Nanotech. 5, 726-734 (2014). doi:10.3762/bjnano.5.85

57. R. Bogue, Graphene sensors: a review of recent developments. Sensor Rev. 34(3), 233-238 (2014). doi:10.1108/Sr-03-2014631

58. W.J. Yuan, G.Q. Shi, Graphene-based gas sensors. J. Mater. Chem. A 1(35), 10078-10091 (2013). doi:10.1039/C3ta11774j

59. T. Seiyama, A. Kato, K. Fujiishi, M. Nagatani, A new detector for gaseous components using semiconductive thin films. Anal. Chem. 34(11), 1502-1503 (1962). doi:10.1021/ac60191a001

60. P.J. Shaver, Activated tungsten oxide gas detectors. Appl. Phys. Lett. 11(8), 255 (1967). doi:10.1063/1.1755123

61. Z.Q. Wu, X.D. Chen, S.B. Zhu, Z.W. Zhou, Y. Yao, W. Quan, B. Liu, Enhanced sensitivity of ammonia sensor using graphene/ polyaniline nanocomposite. Sens. Actuators B 178, 485-493 (2013). doi:10.1016/j.snb.2013.01.014

62. E. Akbari, R. Yusof, M.T. Ahmadi, A. Enzevaee, M.J. Kiani, H. Karimi, M. Rahmani, Bilayer graphene application on $\mathrm{NO}_{2}$ sensor modelling. J. Nanomater. 2014, 1-7 (2014). doi:10.1155/ 2014/534105

63. N.T. Hu, Y.Y. Wang, J. Chai, R.G. Gao, Z. Yang, E.S.W. Kong, Y.F. Zhang, Gas sensor based on p-phenylenediamine reduced graphene oxide. Sens. Actuators B 163(1), 107-114 (2012). doi:10.1016/j.snb.2012.01.016

64. K.S. Subrahmanyam, L.S. Panchakarla, A. Govindaraj, C.N.R. Rao, Simple method of preparing graphene flakes by an arcdischarge method. J. Phys. Chem. C 113(11), 4257-4259 (2009). doi:10.1021/Jp900791y

65. K.S. Subrahmanyam, S.R.C. Vivekchand, A. Govindaraj, C.N.R. Rao, A study of graphenes prepared by different methods: characterization, properties and solubilization. J. Mater. Chem. 18(13), 1517-1523 (2008). doi:10.1039/B716536f

66. R. Paola, H. Anming, C. Giuseppe, Synthesis, properties and potential applications of porous graphene: a review. Nano-Micro Lett. 5(4), 260-273 (2013). doi:10.5101/nml.v5i4.p260-273

67. Z. Yang, R.G. Gao, N.T. Hu, J. Chai, Y.W. Cheng, L.Y. Zhang, H. Wei, E.S.W. Kong, Y.F. Zhang, The prospective two-dimensional graphene nanosheets: preparation, functionalization, and applications. Nano-Micro Lett. 4(1), 1-9 (2012). doi:10. 3786/nml.v4i1.p1-9

68. C. Berger, Z.M. Song, T.B. Li, X.B. Li, A.Y. Ogbazghi et al., Ultrathin epitaxial graphite: 2D electron gas properties and a route toward graphene-based nanoelectronics. J. Phys. Chem. B 108(52), 19912-19916 (2004). doi:10.1021/Jp040650f

69. T.A. Land, T. Michely, R.J. Behm, J.C. Hemminger, G. Comsa, STM investigation of single layer graphite structures produced on $\operatorname{Pt}(111)$ by hydrocarbon decomposition. Surf. Sci. 264(3), 261-270 (1992). doi:10.1016/0039-6028(92)90183-7

70. S. Marchini, S. Gunther, J. Wintterlin, Scanning tunneling microscopy of graphene on Ru(0001). Phys. Rev. B 76, 075429 (2007). doi:10.1103/Physrevb.76.075429

71. J. Coraux, A.T. N'Diaye, C. Busse, T. Michely, Structural coherency of graphene on $\operatorname{Ir}(111)$. Nano Lett. 8(2), 565-570 (2008). doi:10.1021/n10728874

72. V.C. Tung, M.J. Allen, Y. Yang, R.B. Kaner, High-throughput solution processing of large-scale graphene. Nat. Nanotechnol. 4(1), 25-29 (2009). doi:10.1038/nnano.2008.329

73. B.C. Brodie, On the atomic weight of graphite. Philos. Trans. R. Soc. Lond. 149, 249-259 (1859). doi:10.1098/rstl.1859.0013

74. L. Staudenmaier, Verfahren zur darstellung der graphitsäure. Ber. Dtsch. Chem. Ges. 31(2), 1481-1487 (1898). doi:10.1002/ cber. 18980310237

75. W.S. Hummers, R.E. Offeman, Preparation of graphitic oxide. JACS 80(6), 1339-1339 (1958). doi:10.1021/ja01539a017

76. J.Y. Cao, L.Z. Song, J.L. Tang, J. Xu, W.C. Wang, Z.D. Chen, Enhanced activity of Pd nanoparticles supported on Vulcan XC72R carbon pretreated via a modified Hummers method for formic acid electrooxidation. Appl. Surf. Sci. 274, 138-143 (2013). doi:10.1016/j.apsusc.2013.02.133

77. C. Botas, P. Alvarez, P. Blanco, M. Granda, C. Blanco et al., Graphene materials with different structures prepared from the same graphite by the Hummers and Brodie methods. Carbon 65, 156-164 (2013). doi:10.1016/j.carbon.2013.08.009

78. T. Chen, B. Zeng, J.L. Liu, J.H. Dong, X.Q. Liu, Z. Wu, X.Z. Yang, Z.M. Li, High throughput exfoliation of graphene oxide from expanded graphite with assistance of strong oxidant in modified hummers method. J. Phys. Conf. Ser. 188, 012051 (2009). doi:10.1088/1742-6596/188/1/012051

79. C.I. Chang, K.H. Chang, H.H. Shen, C.C. Hu, A unique two-step Hummers method for fabricating low-defect graphene oxide nanoribbons through exfoliating multiwalled carbon nanotubes. J. Taiwan. Inst. Chem. E 45(5), 2762-2769 (2014). doi:10.1016/ j.jtice.2014.05.030 
80. H.C. Schniepp, J.L. Li, M.J. McAllister, H. Sai, M. HerreraAlonso et al., Functionalized single graphene sheets derived from splitting graphite oxide. J. Phys. Chem. B 110(17), 8535-8539 (2006). doi:10.1021/jp060936f

81. X. Fan, W. Peng, Y. Li, X. Li, S. Wang, G. Zhang, F. Zhang, Deoxygenation of exfoliated graphite oxide under alkaline conditions: a green route to graphene preparation. Adv. Mater. 20(23), 4490-4493 (2008). doi:10.1002/adma.200801306

82. G. Wang, J. Yang, J. Park, X. Gou, B. Wang, H. Liu, J. Yao, Facile synthesis and characterization of graphene nanosheets. J. Phys. Chem. C 112(22), 8192-8195 (2008). doi:10.1021/ jp710931h

83. H.-J. Shin, K.K. Kim, A. Benayad, S.-M. Yoon, H.K. Park et al., Efficient reduction of graphite oxide by sodium borohydride and its effect on electrical conductance. Adv. Funct. Mater. 19(12), 1987-1992 (2009). doi:10.1002/adfm.200900167

84. M. Zhou, Y. Wang, Y. Zhai, J. Zhai, W. Ren, F. Wang, S. Dong, Controlled synthesis of large-area and patterned electrochemically reduced graphene oxide films. Chemistry15(25), 6116-6120 (2009). doi:10.1002/chem.200900596

85. Y. Zhou, Q. Bao, L.A.L. Tang, Y. Zhong, K.P. Loh, Hydrothermal dehydration for the "green" reduction of exfoliated graphene oxide to graphene and demonstration of tunable optical limiting properties. Chem. Mater. 21(13), 2950-2956 (2009). doi:10.1021/cm9006603

86. W. Chen, L. Yan, P.R. Bangal, Preparation of graphene by the rapid and mild thermal reduction of graphene oxide induced by microwaves. Carbon 48(4), 1146-1152 (2010). doi:10.1016/j. carbon.2009.11.037

87. Z. Fan, K. Wang, T. Wei, J. Yan, L. Song, B. Shao, An environmentally friendly and efficient route for the reduction of graphene oxide by aluminum powder. Carbon 48(5), 1686-1689 (2010). doi:10.1016/j.carbon.2009.12.063

88. M.J. Fernandez-Merino, L. Guardia, J.I. Paredes, S. VillarRodil, P. Solis-Fernandez, A. Martinez-Alonso, J.M.D. Tascon, Vitamin $\mathrm{C}$ is an ideal substitute for hydrazine in the reduction of graphene oxide suspensions. J. Phys. Chem. C 114(14), 6426-6432 (2010). doi:10.1021/jp100603h

89. X. Gao, J. Jang, S. Nagase, Hydrazine and thermal reduction of graphene oxide: reaction mechanisms, product structures, and reaction design. J. Phys. Chem. C 114(2), 832-842 (2010). doi:10.1021/jp909284g

90. S. Mao, G. Lu, K. Yu, Z. Bo, J. Chen, Specific protein detection using thermally reduced graphene oxide sheet decorated with gold nanoparticle-antibody conjugates. Adv. Mater. 22(32), 3521-3526 (2010). doi:10.1002/adma.201000520

91. S. Pei, J. Zhao, J. Du, W. Ren, H.-M. Cheng, Direct reduction of graphene oxide films into highly conductive and flexible graphene films by hydrohalic acids. Carbon 48(15), 4466-4474 (2010). doi:10.1016/j.carbon.2010.08.006

92. V.H. Pham, T.V. Cuong, T.-D. Nguyen-Phan, H.D. Pham, E.J. Kim, S.H. Hur, E.W. Shin, S. Kim, J.S. Chung, One-step synthesis of superior dispersion of chemically converted graphene in organic solvents. Chem. Commun. 46(24), 4375-4377 (2010). doi:10.1039/c0cc00363h

93. J. Zhang, H. Yang, G. Shen, P. Cheng, J. Zhang, S. Guo, Reduction of graphene oxide via L-ascorbic acid. Chem. Commun. 46(7), 1112-1114 (2010). doi:10.1039/b917705a

94. J. Zhao, S. Pei, W. Ren, L. Gao, H.-M. Cheng, Efficient preparation of large-area graphene oxide sheets for transparent conductive films. ACS Nano 4(9), 5245-5252 (2010). doi:10. $1021 / \mathrm{nn} 1015506$

95. C. Zhu, S. Guo, Y. Fang, S. Dong, Reducing Sugar: New functional molecules for the green synthesis of graphene nanosheets. ACS Nano 4(4), 2429-2437 (2010). doi:10.1021/ nn1002387
96. Z.-J. Fan, W. Kai, J. Yan, T. Wei, L.-J. Zhi, J. Feng, Y.-M. Ren, L.-P. Song, F. Wei, Facile synthesis of graphene nanosheets via Fe reduction of exfoliated graphite oxide. ACS Nano 5(1), 191-198 (2011). doi:10.1021/nn102339t

97. Y. Guo, B. Wu, H. Liu, Y. Ma, Y. Yang, J. Zheng, G. Yu, Y. Liu, Electrical assembly and reduction of graphene oxide in a single solution step for use in flexible sensors. Adv. Mater. 23(40), 4626-4630 (2011). doi:10.1002/adma.201103120

98. D. Luo, G. Zhang, J. Liu, X. Sun, Evaluation criteria for reduced graphene oxide. J. Phys. Chem. C 115(23), 11327-11335 (2011). doi:10.1021/jp110001y

99. P. Sungjin, A. Jinho, J.R. Potts, A. Velamakanni, S. Murali, R.S. Ruoff, Hydrazine-reduction of graphite- and graphene oxide. Carbon 49(9), 3019-3023 (2011). doi:10.1016/j.carbon.2011.02. 071

100. O. Akhavan, M. Kalaee, Z.S. Alavi, S.M.A. Ghiasi, A. Esfandiar, Increasing the antioxidant activity of green tea polyphenols in the presence of iron for the reduction of graphene oxide. Carbon 50(8), 3015-3025 (2012). doi:10.1016/j.carbon.2012.02. 087

101. A. Ambrosi, C.K. Chua, A. Bonanni, M. Pumera, Lithium aluminum hydride as reducing agent for chemically reduced graphene oxides. Chem. Mater. 24(12), 2292-2298 (2012). doi:10. $1021 / \mathrm{cm} 300382 \mathrm{~b}$

102. Y. Shen, T. Jing, W. Ren, J. Zhang, Z.-G. Jiang, Z.-Z. Yu, A. Dasari, Chemical and thermal reduction of graphene oxide and its electrically conductive polylactic acid nanocomposites. Compos. Sci. Technol. 72(12), 1430-1435 (2012). doi:10.1016/ j.compscitech.2012.05.018

103. P. Solis-Fernandez, R. Rozada, J.I. Paredes, S. Villar-Rodil, M.J. Fernandez-Merino, L. Guardia, A. Martinez-Alonso, J.M.D. Tascon, Chemical and microscopic analysis of graphene prepared by different reduction degrees of graphene oxide. J. Alloys Compd. 536, S532-S537 (2012). doi:10.1016/j.jallcom.2012.01. 102

104. D. Thanh Truong, P. Viet Hung, V. Bao Khanh, S.H. Hur, E.W. Shin, E.J. Kim, J.S. Chung, J.M.D. Tascon, Clean and effective catalytic reduction of graphene oxide using atomic hydrogen spillover on $\mathrm{Pt} / \mathrm{gamma}-\mathrm{Al}_{2} \mathrm{O}_{3}$ catalyst. Mater. Lett. 86, 161-164 (2012). doi:10.1016/j.matlet.2012.07.063

105. C.K. Chua, M. Pumera, Reduction of graphene oxide with substituted borohydrides. J. Mater. Chem. A 1(5), 1892-1898 (2013). doi:10.1039/c2ta00665k

106. P. Liu, Y. Huang, L. Wang, A facile synthesis of reduced graphene oxide with $\mathrm{Zn}$ powder under acidic condition. Mater. Lett. 91, 125-128 (2013). doi:10.1016/j.matlet.2012.09.085

107. X.L. Huang, N.T. Hu, Y.Y. Wang, Y.F. Zhang, Ammonia gas sensor based on aniline reduced graphene oxide. Adv. Mater. Res. 669, 79-84 (2013). doi:10.4028/www.scientific.net/AMR. 669.79

108. X.L. Huang, N.T. Hu, L.L. Zhang, L.M. Wei, H. Wei, Y.F. Zhang, The $\mathrm{NH}_{3}$ sensing properties of gas sensors based on aniline reduced graphene oxide. Synth. Met. 185, 25-30 (2013). doi:10.1016/j.synthmet.2013.09.034

109. Y.L. Dong, X.F. Zhang, X.L. Cheng, Y.M. Xu, S. Gao, H. Zhao, L.H. Huo, Highly selective $\mathrm{NO}_{2}$ sensor at room temperature based on nanocomposites of hierarchical nanosphere-like alpha$\mathrm{Fe}_{2} \mathrm{O}_{3}$ and reduced graphene oxide. RSC Adv. 4(101), 57493-57500 (2014). doi:10.1039/C4ra10136g

110. C. Xiangfeng, H. Tao, G. Feng, D. Yongping, S. Wenqi, B. Linshan, Gas sensing properties of graphene- $\mathrm{WO}_{3}$ composites prepared by hydrothermal method. Mat. Sci. Eng. B 193, 97-104 (2015). doi:10.1016/j.mseb.2014.11.011

111. S. Deng, V. Tjoa, H.M. Fan, H.R. Tan, D.C. Sayle, M. Olivo, S. Mhaisalkar, J. Wei, C.H. Sow, Reduced graphene oxide conjugated $\mathrm{Cu}_{2} \mathrm{O}$ nanowire mesocrystals for high-performance $\mathrm{NO}_{2}$ 
gas sensor. JACS 134(10), 4905-4917 (2012). doi:10.1021/ ja211683m

112. M. Gautam, A.H. Jayatissa, Ammonia gas sensing behavior of graphene surface decorated with gold nanoparticles. Solid-State Electron. 78, 159-165 (2012). doi:10.1016/j.sse.2012.05.059

113. F. Yavari, E. Castillo, H. Gullapalli, P.M. Ajayan, N. Koratkar, High sensitivity detection of $\mathrm{NO}_{2}$ and $\mathrm{NH}_{3}$ in air using chemical vapor deposition grown graphene. Appl. Phys. Lett. 100, 203120 (2012). doi:10.1063/1.4720074

114. Y. Seekaew, S. Lokavee, D. Phokharatkul, A. Wisitsoraat, T. Kerdcharoen, C. Wongchoosuk, Low-cost and flexible printed graphene-PEDOT:PSS gas sensor for ammonia detection. Org. Electron. 15(11), 2971-2981 (2014). doi:10.1016/j.orgel.2014. 08.044

115. X. Huang, N. Hu, R. Gao, Y. Yu, Y. Wang, Z. Yang, E. Siu-Wai Kong, H. Wei, Y. Zhang, Reduced graphene oxide-polyaniline hybrid: Preparation, characterization and its applications for ammonia gas sensing. J. Mater. Chem. 22(42), 22488 (2012). doi:10.1039/c2jm34340a

116. N. Hu, Z. Yang, Y. Wang, L. Zhang, Y. Wang, X. Huang, H. Wei, L. Wei, Y. Zhang, Ultrafast and sensitive room temperature $\mathrm{NH}_{3}$ gas sensors based on chemically reduced graphene oxide. Nanotechnology 25(2), 025502 (2014). doi:10.1088/ 0957-4484/25/2/025502

117. Y. Wang, L. Zhang, N. Hu, Y. Wang, Y. Zhang, Z. Zhou, Y. Liu, S. Shen, C. Peng, Ammonia gas sensors based on chemically reduced graphene oxide sheets self-assembled on $\mathrm{Au}$ electrodes. Nanoscale Res. Lett. 9(1), 251 (2014). doi:10.1186/ 1556-276X-9-251

118. M. Gautam, A.H. Jayatissa, Graphene based field effect transistor for the detection of ammonia. J. Appl. Phys. 112, 064304 (2012). doi:10.1063/1.4752272

119. Z. Ben Aziza, Q. Zhang, D. Baillargeat, Graphene/mica based ammonia gas sensors. Appl. Phys. Lett. 105, 254102 (2014). doi:10.1063/1.4905039

120. A. Inaba, K. Yoo, Y. Takei, K. Matsumoto, I. Shimoyama, Ammonia gas sensing using a graphene field-effect transistor gated by ionic liquid. Sens. Actuators B 195, 15-21 (2014). doi:10.1016/j.snb.2013.12.118

121. Z.B. Ye, Y.D. Jiang, H.L. Tai, Z. Yuan, The investigation of reduced graphene oxide/P3HT composite films for ammonia detection. Integr. Ferroelectr. 154(1), 73-81 (2014). doi:10. 1080/10584587.2014.904148

122. S. Yoo, X. Li, Y. Wu, W.H. Liu, X.L. Wang, W.H. Yi, Ammonia gas detection by tannic acid functionalized and reduced graphene oxide at room temperature. J. Nanomater. 2014, 1-6 (2014). doi:10.1155/2014/497384

123. H. Meng, W. Yang, K. Ding, L. Feng, Y.F. Guan, $\mathrm{Cu}_{2} \mathrm{O}$ nanorods modified by reduced graphene oxide for $\mathrm{NH}_{3}$ sensing at room temperature. J. Mater. Chem. A 3(3), 1174-1181 (2015). doi:10.1039/C4ta06024e

124. H. Choi, H.Y. Jeong, D.S. Lee, C.G. Choi, S.Y. Choi, Flexible $\mathrm{NO}_{2}$ gas sensor using multilayer graphene films by chemical vapor deposition. Carbon Lett. 14(3), 186-189 (2013). doi:10. 5714/Cl.2013.14.3.186

125. L.T. Hoa, H.N. Tien, V.H. Luan, J.S. Chung, S.H. Hur, Fabrication of a novel 2D-graphene/2D-NiO nanosheet-based hybrid nanostructure and its use in highly sensitive $\mathrm{NO}_{2}$ sensors. Sens. Actuators B 185, 701-705 (2013). doi:10.1016/j.snb.2013.05. 050

126. L. Huang, Z. Wang, J. Zhang, J. Pu, Y. Lin, S. Xu, L. Shen, Q. Chen, W. Shi, Fully printed, rapid-response sensors based on chemically modified graphene for detecting $\mathrm{NO}_{2}$ at room temperature. ACS Appl. Mater. Interface 6(10), 7426-7433 (2014). doi:10.1021/am500843p
127. Y. Ju Yun, W.G. Hong, N.-J. Choi, B. Hoon Kim, Y. Jun, H.-K. Lee, Ultrasensitive and highly selective graphene-based single yarn for use in wearable gas sensor. Sci. Rep. 5, 10904-10904 (2015). doi:10.1038/srep10904

128. R. Pearce, T. Iakimov, M. Andersson, L. Hultman, A.L. Spetz, R. Yakimova, Epitaxially grown graphene based gas sensors for ultra sensitive $\mathrm{NO}_{2}$ detection. Sens. Actuators B 155(2), 451-455 (2011). doi:10.1016/j.snb.2010.12.046

129. M.G. Chung, D.H. Kim, H.M. Lee, T. Kim, J.H. Choi, D.K. Seo, J.B. Yoo, S.H. Hong, T.J. Kang, Y.H. Kim, Highly sensitive $\mathrm{NO}_{2}$ gas sensor based on ozone treated graphene. Sens. Actuators B 166, 172-176 (2012). doi:10.1016/j.snb.2012.02.036

130. C. Lee, J. Ahn, K.B. Lee, D. Kim, J. Kim, Graphene-based flexible $\mathrm{NO}_{2}$ chemical sensors. Thin Solid Films 520(16), 5459-5462 (2012). doi:10.1016/j.tsf.2012.03.095

131. S. Srivastava, K. Jain, V.N. Singh, S. Singh, N. Vijayan, N. Dilawar, G. Gupta, T.D. Senguttuvan, Faster response of $\mathrm{NO}(2)$ sensing in graphene-WO(3) nanocomposites. Nanotechnology 23(20), 205501 (2012). doi:10.1088/0957-4484/23/20/205501

132. J.L. Huang, G.Z. Xie, Y. Zhou, T. Xie, H.L. Tai, G.J. Yang, Polyvinylpyrrolidone/reduced graphene oxide nanocomposites thin films coated on quartz crystal microbalance for $\mathrm{NO}_{2}$ detection at room temperature. Proc. SPIE 9285, 92850B92851B (2014). doi:10.1117/12.2069492

133. S. Liu, B. Yu, H. Zhang, T. Fei, T. Zhang, Enhancing $\mathrm{NO}_{2}$ gas sensing performances at room temperature based on reduced graphene oxide- $\mathrm{ZnO}$ nanoparticles hybrids. Sens. Actuators B 202, 272-278 (2014). doi:10.1016/j.snb.2014.05.086

134. X. Liu, J.S. Cui, J.B. Sun, X.T. Zhang, 3D graphene aerogelsupported $\mathrm{SnO}_{2}$ nanoparticles for efficient detection of $\mathrm{NO}_{2}$. RSC Adv. 4(43), 22601-22605 (2014). doi:10.1039/C4ra02453b

135. C. Piloto, M. Notarianni, M. Shafiei, E. Taran, D. Galpaya, C. Yan, N. Motta, Highly $\mathrm{NO}_{2}$ sensitive caesium doped graphene oxide conductometric sensors. Beilstein. J. Nanotechnol. 5, 1073-1081 (2014). doi:10.3762/bjnano.5.120

136. P.G. Su, H.C. Shieh, Flexible $\mathrm{NO}_{2}$ sensors fabricated by layerby-layer covalent anchoring and in situ reduction of graphene oxide. Sens. Actuators B 190, 865-872 (2014). doi:10.1016/j. snb.2013.09.078

137. H. Zhang, J.C. Feng, T. Fei, S. Liu, T. Zhang, $\mathrm{SnO}_{2}$ nanoparticles-reduced graphene oxide nanocomposites for $\mathrm{NO}_{2}$ sensing at low operating temperature. Sens. Actuators B 190, 472-478 (2014). doi:10.1016/j.snb.2013.08.067

138. P.-G. Su, S.-L. Peng, Fabrication and $\mathrm{NO}_{2}$ gas-sensing properties of reduced graphene oxide/ $\mathrm{WO}_{3}$ nanocomposite films. Talanta 132, 398-405 (2015). doi:10.1016/j.Talanta2014.09.034

139. F. Gu, R. Nie, D. Han, Z. Wang, $\mathrm{In}_{2} \mathrm{O}_{3}$-graphene nanocomposite based gas sensor for selective detection of $\mathrm{NO}_{2}$ at room temperature. Sens. Actuators B 219, 94-99 (2015). doi:10.1016/j. snb.2015.04.119

140. J.L. Johnson, A. Behnam, S.J. Pearton, A. Ural, Hydrogen sensing using pd-functionalized multi-layer graphene nanoribbon networks. Adv. Mater. 22(43), 4877-4880 (2010). doi:10. 1002/adma.201001798

141. B.H. Chu, C.F. Lo, J. Nicolosi, C.Y. Chang, V. Chen, W. Strupinski, S.J. Pearton, F. Ren, Hydrogen detection using platinum coated graphene grown on SiC. Sens. Actuators B 157(2), 500-503 (2011). doi:10.1016/j.snb.2011.05.007

142. B.H. Chu, J. Nicolosi, C.F. Lo, W. Strupinski, S.J. Pearton, F. Ren, Effect of coated platinum thickness on hydrogen detection sensitivity of graphene-based sensors. Electrochem. Solid-State Lett. 14(7), K43-K45 (2011). doi:10.1149/1.3589250

143. R. Kumar, D. Varandani, B.R. Mehta, V.N. Singh, Z. Wen, X. Feng, K. Muellen, Fast response and recovery of hydrogen sensing in Pd-Pt nanoparticle-graphene composite layers. 
Nanotechnology 22(27), 275719 (2011). doi:10.1088/09574484/22/27/275719

144. Q.G. Jiang, Z.M. Ao, W.T. Zheng, S. Li, Q. Jiang, Enhanced hydrogen sensing properties of graphene by introducing a monoatom-vacancy. Phys. Chem. Chem. Phys. 15(48), 21016-21022 (2013). doi:10.1039/c3cp52976b

145. A. Kaniyoor, R.I. Jafri, T. Arockiadoss, S. Ramaprabhu, Nanostructured Pt decorated graphene and multi walled carbon nanotube based room temperature hydrogen gas sensor. Nanoscale 1(3), 382-386 (2009). doi:10.1039/b9nr00015a

146. M. Shafiei, P.G. Spizzirri, R. Arsat, J. Yu, J. du Plessis, S. Dubin, R.B. Kaner, K. Kalantar-Zadeh, W. Wlodarski, Platinum/graphene nanosheet/SiC contacts and their application for hydrogen gas sensing. J. Phys. Chem. C 114(32), 13796-13801 (2010). doi:10.1021/jp104459s

147. U. Lange, T. Hirsch, V.M. Mirsky, O.S. Wolfbeis, Hydrogen sensor based on a graphene: palladium nanocomposite. Electrochimi. Acta 56(10), 3707-3712 (2011). doi:10.1016/j.elec tacta.2010.10.078

148. M.G. Chung, D.-H. Kim, D.K. Seo, T. Kim, H.U. Im, H.M. Lee, J.-B. Yoo, S.-H. Hong, T.J. Kang, Y.H. Kim, Flexible hydrogen sensors using graphene with palladium nanoparticle decoration. Sens. Actuators B 169, 387-392 (2012). doi:10.1016/j.snb.2012. 05.031

149. R.C. Ehemann, P.S. Krstic, J. Dadras, P.R.C. Kent, J. Jakowski, Detection of hydrogen using graphene. Nanoscale Res. Lett. 7, 1-14 (2012). doi:10.1186/1556-276x-7-198

150. A. Esfandiar, S. Ghasemi, A. Irajizad, O. Akhavan, M.R. Gholami, The decoration of $\mathrm{TiO}_{2}$ /reduced graphene oxide by $\mathrm{Pd}$ and Pt nanoparticles for hydrogen gas sensing. Int. J. Hydrogen Energ. 37(20), 15423-15432 (2012). doi:10.1016/j.ijhydene. 2012.08.011

151. P.A. Russo, N. Donato, S.G. Leonardi, S. Baek, D.E. Conte, G. Neri, N. Pinna, Room-temperature hydrogen sensing with heteronanostructures based on reduced graphene oxide and tin oxide. Angew. Chem. Int. Ed. 51(44), 11053-11057 (2012). doi:10.1002/anie.201204373

152. X. Chen, F.M. Yasin, P.K. Eggers, R.A. Boulos, X. Duan, R.N. Lamb, K.S. Iyer, C.L. Raston, Non-covalently modified graphene supported ultrafine nanoparticles of palladium for hydrogen gas sensing. RSC Adv. 3(10), 3213-3217 (2013). doi: $10.1039 / \mathrm{c} 3 \mathrm{ra} 22986 \mathrm{f}$

153. D.-T. Phan, G.-S. Chung, Characteristics of resistivity-type hydrogen sensing based on palladium-graphene nanocomposites. Int. J. Hydrogen Energ. 39(1), 620-629 (2014). doi:10. 1016/j.ijhydene.2013.08.107

154. B. Singh, J. Wang, S. Rathi, G.-H. Kim, Alignment of graphene oxide nanostructures between microgap electrodes via dielectrophoresis for hydrogen gas sensing applications. Appl. Phys. Lett. 106, 203106 (2015). doi:10.1063/1.4921524

155. J. Hong, S. Lee, J. Seo, S. Pyo, J. Kim, T. Lee, A highly sensitive hydrogen sensor with gas selectivity using a PMMA membrane-coated Pd nanoparticle/single-layer graphene hybrid. ACS Appl. Mater. Interface 7(6), 3554-3561 (2015). doi:10. 1021/am5073645

156. Z. Zhang, X. Zou, L. Xu, L. Liao, W. Liu, J. Ho, X. Xiao, C. Jiang, J. Li, Hydrogen gas sensor based on metal oxide nanoparticles decorated graphene transistor. Nanoscale 7(22), 10078-10084 (2015). doi:10.1039/c5nr01924a

157. Y. Zheng, D. Lee, H.Y. Koo, S. Maeng, Chemically modified graphene/PEDOT:PSS nanocomposite films for hydrogen gas sensing. Carbon 81, 54-62 (2015). doi:10.1016/j.carbon.2014. 09.023

158. K.R. Nemade, S.A. Waghuley, Chemiresistive gas sensing by few-layered graphene. J. Electron. Mater. 42(10), 2857-2866 (2013). doi:10.1007/s11664-013-2699-4
159. K.R. Nemade, A. Waghuley, Carbon dioxide gas sensing application of graphene $/ \mathrm{Y}_{2} \mathrm{O}_{3}$ quantum dots composite. Int. J. Mod. Phys. 22, 380-384 (2013). doi:10.1142/s2010194513010404

160. K.R. Nemade, S.A. Waghuley, Role of defects concentration on optical and carbon dioxide gas sensing properties of $\mathrm{Sb}_{2} \mathrm{O}_{3} /$ graphene composites. Opt. Mater. 36(3), 712-716 (2014). doi:10.1016/j.optmat.2013.11.024

161. K.R. Nemade, S.A. Waghuley, Highly responsive carbon dioxide sensing by graphene/ $\mathrm{Al}_{2} \mathrm{O}_{3}$ quantum dots composites at low operable temperature. Indian J. Phys. 88(6), 577-583 (2014). doi:10.1007/s12648-014-0454-1

162. C.-S. Liu, R. Jia, X.-J. Ye, Z. Zeng, Non-hexagonal symmetryinduced functional $\mathrm{T}$ graphene for the detection of carbon monoxide. J. Chem. Phys. 139(3), 034704 (2013). doi:10.1063/ 1.4813528

163. Z. Wu, X. Chen, S. Zhu, Z. Zhou, Y. Yao, W. Quan, B. Liu, Room temperature methane sensor based on graphene nanosheets/polyaniline nanocomposite thin film. IEEE Sens. J. 13(2), 777-782 (2013). doi:10.1109/jsen.2012.2227597

164. H.J. Yoon, D.H. Jun, J.H. Yang, Z.X. Zhou, S.S. Yang, M.M.-C. Cheng, Carbon dioxide gas sensor using a graphene sheet. Sens. Actuators B 157(1), 310-313 (2011). doi:10.1016/j.snb.2011.03. 035

165. S.M. Hafiz, R. Ritikos, T.J. Whitcher, N.M. Razib, D.C.S. Bien et al., A practical carbon dioxide gas sensor using room-temperature hydrogen plasma reduced graphene oxide. Sens. Actuators B 193, 692-700 (2014). doi:10.1016/j.snb.2013.12. 017

166. F. Shen, D. Wang, R. Liu, X. Pei, T. Zhang, J. Jin, Edge-tailored graphene oxide nanosheet-based field effect transistors for fast and reversible electronic detection of sulfur dioxide. Nanoscale 5(2), 537-540 (2013). doi:10.1039/c2nr32752j

167. X.-Y. Liu, J.-M. Zhang, K.-W. Xu, V. Ji, Improving $\mathrm{SO}_{2}$ gas sensing properties of graphene by introducing dopant and defect: a first-principles study. Appl. Surf. Sci. 313, 405-410 (2014). doi:10.1016/j.apsusc.2014.05.223

168. L. Shao, G. Chen, H. Ye, H. Niu, Y. Wu, Y. Zhu, B. Ding, Sulfur dioxide molecule sensors based on zigzag graphene nanoribbons with and without $\mathrm{Cr}$ dopant. Phys. Lett. A 378(7-8), 667-671 (2014). doi:10.1016/j.physleta.2013.12.042

169. Q. Xian, M. Qingyuan, F. Yuan, Ping, Strain effects on enhanced hydrogen sulphide detection capability of Ag-decorated defective graphene. Mod. Phys. Lett. B 26(25), 1250166 (2012). doi:10.1142/s0217984912501667

170. L. Zhou, F. Shen, X. Tian, D. Wang, T. Zhang, W. Chen, Stable $\mathrm{Cu}_{2} \mathrm{O}$ nanocrystals grown on functionalized graphene sheets and room temperature $\mathrm{H}_{2} \mathrm{~S}$ gas sensing with ultrahigh sensitivity. Nanoscale 5(4), 1564-1569 (2013). doi:10.1039/ c2 2 r $33164 \mathrm{k}$

171. Z. Jiang, J. Li, H. Aslan, Q. Li, Y. Li et al., A high efficiency $\mathrm{H}_{2} \mathrm{~S}$ gas sensor material: paper like $\mathrm{Fe}_{2} \mathrm{O}_{3}$ /graphene nanosheets and structural alignment dependency of device efficiency. J. Mater. Chem. A 2(19), 6714-6717 (2014). doi:10.1039/ c3ta15180h

172. Y. Ren, C. Zhu, W. Cai, H. Li, H. Ji, I. Kholmanov, Y. Wu, R.D. Piner, R.S. Ruoff, Detection of sulfur dioxide gas with graphene field effect transistor. Appl. Phys. Lett. 100, 163114 (2012). doi:10.1063/1.4704803

173. Q. Xian, M. Qing, Yuan, G. Yu Fei, Ag supported Si-doped graphene for hydrogen sulphide detection: a first-principles investigation. Adv. Mater. Res. 602-604, 37-40 (2013). doi:10. 4028/www.scientific.net/AMR.602-604.37

174. Y.-H. Zhang, L.-F. Han, Y.-H. Xiao, D.-Z. Jia, Z.-H. Guo, F. Li, Understanding dopant and defect effect on $\mathrm{H}_{2} \mathrm{~S}$ sensing performances of graphene: a first-principles study. Comp. Mater. Sci. 69, 222-228 (2013). doi:10.1016/j.commatsci.2012.11.048 
175. S. Cho, J.S. Lee, J. Jun, S.G. Kim, J. Jang, Fabrication of waterdispersible and highly conductive PSS-doped PANI/graphene nanocomposites using a high-molecular weight PSS dopant and their application in $\mathrm{H}_{2} \mathrm{~S}$ detection. Nanoscale 6(24), 15181-15195 (2014). doi:10.1039/c4nr04413d

176. S.-J. Choi, B.-H. Jang, S.-J. Lee, B.K. Min, A. Rothschild, I.-D. $\mathrm{Kim}$, Selective detection of acetone and hydrogen sulfide for the diagnosis of diabetes and halitosis using $\mathrm{SnO}_{2}$ nanofibers functionalized with reduced graphene oxide nanosheets. ACS Appl. Mater. Interface 6(4), 2588-2597 (2014). doi:10.1021/am405088q

177. S.-J. Choi, C. Choi, S.-J. Kim, H.-J. Cho, M. Hakim, S. Jeon, I.D. Kim, Highly efficient electronic sensitization of non-oxidized graphene flakes on controlled pore-loaded $\mathrm{WO}_{3}$ nanofibers for selective detection of $\mathrm{H}_{2} \mathrm{~S}$ molecules. Sci. Rep. 5, 8067 (2015). doi:10.1038/srep08067

178. M. Berahman, M.H. Sheikhi, Hydrogen sulfide gas sensor based on decorated zigzag graphene nanoribbon with copper. Sens. Actuators B 219, 338-345 (2015). doi:10.1016/j.snb.2015.04. 114

179. S.A. Tawfik, X.Y. Cui, D.J. Carter, S.P. Ringer, C. Stampfl, Sensing sulfur-containing gases using titanium and tin decorated zigzag graphene nanoribbons from first-principles. Phys. Chem. Chem. Phys. 17(10), 6925-6932 (2015). doi:10.1039/c4cp05919k

180. V. Dua, S.P. Surwade, S. Ammu, S.R. Agnihotra, S. Jain, K.E. Roberts, S. Park, R.S. Ruoff, S.K. Manohar, All-organic vapor sensor using inkjet-printed reduced graphene oxide. Angew. Chem. Int. Ed. 49(12), 2154-2157 (2010). doi:10.1002/anie. 200905089

181. Z. Jiang, J. Wang, L. Meng, Y. Huang, L. Liu, A highly efficient chemical sensor material for ethanol: $\mathrm{Al}_{2} \mathrm{O}_{3} / \mathrm{Graphene}$ nanocomposites fabricated from graphene oxide. Chem. Commun. 47(22), 6350-6352 (2011). doi:10.1039/c1cc11711d

182. H. Zhang, A. Kulkarni, H. Kim, D. Woo, Y.-J. Kim, B.H. Hong, J.-B. Choi, T. Kim, Detection of acetone vapor using graphene on polymer optical fiber. J. Nanosci. Nanotechno. 11(7), 5939-5943 (2011). doi:10.1166/jnn.2011.4408

183. M. Gautam, A.H. Jayatissa, Detection of organic vapors by graphene films functionalized with metallic nanoparticles. J. Appl. Phys. 112, 114326 (2012). doi:10.1063/1.4768724

184. L. Tang, H. Feng, J. Cheng, J. Li, Uniform and rich-wrinkled electrophoretic deposited graphene film: a robust electrochemical platform for TNT sensing. Chem. Commun. 46(32), 5882-5884 (2010). doi:10.1039/c0cc01212b

185. L. Fan, Y. Hu, X. Wang, L. Zhang, F. Li, D. Han, Z. Li, Q. Zhang, Z. Wang, L. Niu, Fluorescence resonance energy transfer quenching at the surface of graphene quantum dots for ultrasensitive detection of TNT. Talanta 101, 192-197 (2012). doi:10.1016/j.Talanta2012.08.048

186. M. Liu, W. Chen, Graphene nanosheets-supported Ag nanoparticles for ultrasensitive detection of TNT by surfaceenhanced Raman spectroscopy. Biosens. Bioelectron. 46, 68-73 (2013). doi:10.1016/j.bios.2013.01.073

187. V.V. Singh, A.K. Nigam, S.S. Yadav, B.K. Tripathi, A. Srivastava, M. Boopathi, B. Singh, Graphene oxide as carboelectrocatalyst for in situ electrochemical oxidation and sensing of chemical warfare agent simulant. Sens. Actuators B 188, 1218-1224 (2013). doi:10.1016/j.snb.2013.08.013

188. M.D. Ganji, Z. Dalirandeh, A. Khosravi, A. Fereidoon, Aluminum nitride graphene for DMMP nerve agent adsorption and detection. Mater. Chem. Phys. 145(1-2), 260-267 (2014). doi:10.1016/j.matchemphys.2014.02.021

189. B. Chen, H. Liu, X. Li, C. Lu, Y. Ding, B. Lu, Fabrication of a graphene field effect transistor array on microchannels for ethanol sensing. Appl. Surf. Sci. 258(6), 1971-1975 (2012). doi:10.1016/j.apsusc.2011.05.101
190. L. Zhang, C. Li, A. Liu, G. Shi, Electrosynthesis of graphene oxide/polypyrene composite films and their applications for sensing organic vapors. J. Mater. Chem. 22(17), 8438-8443 (2012). doi:10.1039/c2jm16552j

191. P. Sun, Y. Cai, S. Du, X. Xu, L. You, J. Ma, F. Liu, X. Liang, Y. Sun, G. Lu, Hierarchical alpha- $\mathrm{Fe}_{2} \mathrm{O}_{3} / \mathrm{SnO}_{2}$ semiconductor composites: hydrothermal synthesis and gas sensing properties. Sens. Actuators B 182, 336-343 (2013). doi:10.1016/j.snb.2013. 03.019

192. F. Liu, X. Chu, Y. Dong, W. Zhang, W. Sun, L. Shen, Acetone gas sensors based on graphene- $\mathrm{ZnFe}_{2} \mathrm{O}_{4}$ composite prepared by solvothermal method. Sens. Actuators B 188, 469-474 (2013). doi:10.1016/j.snb.2013.06.065

193. M. Moradi, M. Noei, A.A. Peyghan, DFT studies of Si- and Aldoping effects on the acetone sensing properties of $\mathrm{BC}_{3}$ graphene. Mol. Phys. 111(21), 3320-3326 (2013). doi:10.1080/ 00268976.2013.783720

194. X. Wang, X. Sun, P.A. Hu, J. Zhang, L. Wang, W. Feng, S. Lei, B. Yang, W. Cao, Colorimetric sensor based on self-assembled polydiacetylene/graphene-stacked composite film for vaporphase volatile organic compounds. Adv. Funct. Mater. 23(48), 6044-6050 (2013). doi:10.1002/adfm.201301044

195. S.-J. Choi, W.-H. Ryu, S.-J. Kim, H.-J. Cho, I.-D. Kim, Bifunctional co-sensitization of graphene oxide sheets and Ir nanoparticles on p-type $\mathrm{Co}_{3} \mathrm{O}_{4}$ nanofibers for selective acetone detection. J. Mater. Chem. B 2(41), 7160-7167 (2014). doi:10. 1039/c4tb00767k

196. T. Kavinkumar, D. Sastikumar, S. Manivannan, Reduced graphene oxide coated optical fiber for methanol and ethanol vapor detection at room temperature. Proceedings of SPIE 9270, Optoel. Dev. Integr. V, $92700 U$ (2014). doi:10.1117/12.2071841

197. A. Aziz, H.N. Lim, S.H. Girei, M.H. Yaacob, M.A. Mandi, N.M. Huang, A. Pandikumar, Silver/graphene nanocomposite-modified optical fiber sensor platform for ethanol detection in water medium. Sens. Actuators B 206, 119-125 (2015). doi:10.1016/j. snb.2014.09.035

198. A.S.M.I. Uddin, P. Duy-Thach, G.-S. Chung, Low temperature acetylene gas sensor based on Ag nanoparticles-loaded $\mathrm{ZnO}$ reduced graphene oxide hybrid. Sens. Actuators B 207, 362-369 (2015). doi:10.1016/j.snb.2014.10.091

199. A.S.M.I. Uddin, K.-W. Lee, G.-S. Chung, Acetylene gas sensing properties of an Ag-loaded hierarchical $\mathrm{ZnO}$ nanostructuredecorated reduced graphene oxide hybrid. Sens. Actuators B 216, 33-40 (2015). doi:10.1016/j.snb.2015.04.028

200. X. Chaonan, J. Tamaki, N. Miura, N. Yamazoe, Grain size effects on gas sensitivity of porous $\mathrm{SnO}_{2}$-based elements. Sens. Actuators B 3(2), 147-155 (1991). doi:10.1016/09254005(91)80207-Z

201. A. Rothschild, Y. Komem, The effect of grain size on the sensitivity of nanocrystalline metal-oxide gas sensors. J. Appl. Phys. 95(11), 6374-6380 (2004). doi:10.1063/1.1728314

202. J.-H. Lee, Gas sensors using hierarchical and hollow oxide nanostructures: overview. Sens. Actuators B 140(1), 319-336 (2009). doi:10.1016/j.snb.2009.04.026

203. L. Sang-Zi, C. Gugang, A.R. Harutyunyan, J.O. Sofo, Screening of charged impurities as a possible mechanism for conductance change in graphene gas sensing. Phys. Rev. B: Condens. Matter 90(11), 115410 (2014). doi:10.1103/PhysRevB.90.115410

204. N.J. Dayan, S.R. Sainkar, R.N. Karekar, R.C. Aiyer, Formulation and characterization of $\mathrm{ZnO}: \mathrm{Sb}$ thick-film gas sensors. Thin Solid Films 325(1-2), 254-258 (1998). doi:10.1016/s00406090(98)00501-x

205. N. Yamazoe, G. Sakai, K. Shimanoe, Oxide semiconductor gas sensors. Catal. Surv. Asia 7(1), 63-75 (2003). doi:10.1023/a: 1023436725457 
206. N. Yamazoe, New approaches for improving semiconductor gas sensors. Sens. Actuators B 5(1-4), 7-19 (1991). doi:10.1016/ 0925-4005(91)80213-4

207. M. Egashira, Y. Shimizu, Y. Takao, S. Sako, Variations in I-V characteristics of oxide semiconductors induced by oxidizing gases. Sens. Actuators B 35(1-3), 62-67 (1996). doi:10.1016/ s0925-4005(96)02015-1

208. Y. Zhou, Y.D. Jiang, T. Xie, H.L. Tai, G.Z. Xie, A novel sensing mechanism for resistive gas sensors based on layered reduced graphene oxide thin films at room temperature. Sens. Actuators B 203, 135-142 (2014). doi:10.1016/j.snb.2014.06.105

209. M. Zhu, X. Li, S. Chung, L. Zhao, X. Li, X. Zang, K. Wang, J. Wei, M. Zhong, K. Zhou, D. Xie, H. Zhu, Photo-induced selective gas detection based on reduced graphene oxide/Si Schottky diode. Carbon 84, 138-145 (2015). doi:10.1016/j.car bon.2014.12.008

210. R.-C. Wang, Y.-M. Chang, Switch of p-n electricity of reducedgraphene-oxide-flake stacked films enabling room-temperature gas sensing from ultrasensitive to insensitive. Carbon 91, 416-422 (2015). doi:10.1016/j.carbon.2015.05.012

211. F. Yavari, Z.P. Chen, A.V. Thomas, W.C. Ren, H.M. Cheng, N. Koratkar, High sensitivity gas detection using a macroscopic three-dimensional graphene foam network. Sci. Rep. 1, 166 (2011). doi:10.1038/srep00166

212. S. Yi, S.Q. Tian, D.W. Zeng, K. Xu, S.P. Zhang, C.S. Xie, An $\mathrm{In}_{2} \mathrm{O}_{3}$ nanowire-like network fabricated on coplanar sensor surface by sacrificial CNTs for enhanced gas sensing performance. Sens. Actuators B 185, 345-353 (2013). doi:10.1016/j. snb.2013.05.007

213. X. Huang, J. Lin, Z. Pi, Z. Yu, Qualitative and quantitative analysis of organophosphorus pesticide residues using temperature modulated $\mathrm{SnO}(2)$ gas sensor. Talanta 64, 538-545 (2004). doi:10.1016/j.Talanta.2004.03.022

214. X.J. Huang, L.C. Wang, Y.F. Sun, F.L. Meng, J.H. Liu, Quantitative analysis of pesticide residue based on the dynamic response of a single $\mathrm{SnO}_{2}$ gas sensor. Sens. Actuators B 99(2-3), 330-335 (2004). doi:10.1016/j.snb.2003.11.032

215. X.J. Huang, J.H. Liu, D.L. Shao, Z.X. Pi, Z.L. Yu, Rectangular mode of operation for detecting pesticide residue by using a single $\mathrm{SnO}_{2}$-based gas sensor. Sens. Actuators B 96(3), 630-635 (2003). doi:10.1016/j.snb.2003.07.006 